\title{
The Link between Hypersensitivity Syndrome Reaction Development and Human Herpes Virus-6 Reactivation
}

\author{
Joshua C. Pritchett, ${ }^{1}$ Radu M. Nanau, ${ }^{2}$ and Manuela G. Neuman ${ }^{2}$ \\ ${ }^{1}$ HHV-6 Foundation, Santa Barbara, CA 93108, USA \\ ${ }^{2}$ Department of Pharmacology and Toxicology, University of Toronto and In Vitro Drug Safety and Biotechnology, \\ Toronto, ON, Canada M5G $1 L 7$
}

Correspondence should be addressed to Manuela G. Neuman, Manuela.neuman@utoronto.ca

Received 1 February 2012; Accepted 23 February 2012

Academic Editor: Robert E. Winkler

Copyright (c) 2012 Joshua C. Pritchett et al. This is an open access article distributed under the Creative Commons Attribution License, which permits unrestricted use, distribution, and reproduction in any medium, provided the original work is properly cited.

Background. There are challenges in the clinical diagnosis of drug-induced injury and in obtaining information on the reactivation of human herpes viruses (HHV) during idiosyncratic adverse drug reactions. Objectives. (i) To develop a unified list of drugs incriminated in drug-induced hepatotoxicity and severe cutaneous reactions, in which drug hypersensitivity leads to HHV-6 reactivation and further complication of therapy and recovery and (ii) to supplement the already available data on reporting frequencies of liver- or skin-induced cases with knowledge of individual case reports, including HHV-6 reactivation and briefly introducing chromosomally integrated HHV-6. Data Sources and Extraction. Drugs identified as causes of (i) idiosyncratic reactions, (ii) drug-induced hypersensitivity, drug-induced hepatotoxicity, acute liver failure, and Stevens-Johnson syndrome, and (iii) human herpes virus reactivation in PubMed since 1997 have been collected and discussed. Results. Data presented in this paper show that HHV-6 reactivation is associated with more severe organ involvement and a prolonged course of disease. Conclusion. This analysis of HHV-6 reactivation associated with drug-induced severe cutaneous reactions and hepatotoxicity will aid in causality assessment and clinical diagnosis of possible life-threatening events and will provide a basis for further patient characterization and therapy.

\section{Introduction}

A hypersensitivity reaction (HSR) is a host-dependent idiosyncratic adverse drug reaction (ADR) that cannot be predicted by the dose, frequency, or length of the treatment. Furthermore, animal models cannot predict an HSR. A "true" HSR is defined by the triad of fever, rash, and internal organ involvement [1-6]. HSRs occur with an incidence of 1 in 1000 to 1 in 10000 drug exposures, with a mortality rate approaching 10\% [5-8]. Symptoms of HSR can range from general manifestations, such as morbiliform rash, urticaria, angioedema, fever, malaise, anaphylaxis, bronchospasm, and erythema multiforme, to severe cutaneous adverse reactions (SCAR) such as drug-induced hypersensitivity syndrome (DIHS)/drug reaction with eosinophilia and systemic symptoms (DRESS), and Stevens-Johnson syndrome (SJS)/toxic epidermal necrolysis (TEN) [2, 4-7, 9-11]. Cutaneous eruptions are reported in the vast majority of DIHS/DRESS cases, often presenting as maculopapular rash or generalized erythematous rash $[7,8]$. The internal organ most often affected is the liver, with drug-induced liver injury (DILI) presenting as anomalies in liver function tests or the presence of hepatomegaly. Aspartate aminotransferase (AST) and alanine aminotransferase (ALT) were found to be increased an average of 9-10-fold above the upper normal limits in a literature review of 172 DRESS cases [7]. The presence of serum bilirubin raised $>3$ times over the upper limit of normal along with aminotransferase elevations is associated with a more severe set of symptoms than isolated aminotransferase abnormalities alone, an observation known as Hy's Law [12, 13]. Other internal organs, such as kidneys, are less often affected [4, 7]. Hypereosinophilia is the 
third most common symptom of DIHS/DRESS [7]. Skin rash, liver involvement, high-grade fever, hypereosinophilia, lymphadenopathy, and the increased presence of atypical lymphocytes are symptoms associated with DIHS/DRESS cases classified as "probable/definite" based on the RegiSCAR scoring system [7].

Maculopapular rash, erythema multiforme, exfoliative dermatitis, acute generalized exanthematous pustular dermatosis-like eruptions, and erythroderma are types of cutaneous manifestations associated with DIHS, while mucosal involvement is rare. On the other hand, skin and mucosal involvement characterizes SJS/TEN [8]. A further distinction between DIHS/DRESS and SJS/TEN is the time to onset of symptoms, which is often delayed (4-5 weeks) in the former, while it occurs in the early stages of drug exposure (approximately 3 weeks) in the latter [8].

Carbamazepine was the drug most often associated with DRESS among 44 drugs linked to this reaction in 172 cases reported over a period of 12 years [7]. Anticonvulsants such as carbamazepine, phenytoin, phenobarbital, lamotrigine, zonisamide, and sodium valproate are the class of drugs most often related to DIHS/DRESS. Other pharmaceutical agents, including allopurinol, nonsteroidal anti-inflammatory drugs, chlormezanone, aminopenicillins, cephalosporins, quinolones cycline antibiotics, and antiretrovirals, as well as anti-infective sulfonamides, have also been implicated [6$8,11,14-16]$.

SCAR development results in patient hospitalization, and the culprit drug is interrupted on the first day of hospitalization. DILI is often diagnosed during the course of the disease. Corticosteroids are the treatment most often employed. The mean time to recovery was 6.4 weeks in 172 DRESS cases, while death was recorded in $9(5.2 \%)$ patients. Death was connected with a more severe course of reaction, particularly observed in older patients, and often due to liver failure [7].

While the precise mechanism of HSR is unknown, various theories involve the interplay between metabolic and immunologic factors $[2,4,6]$, genetic predisposition, and, more recently, infection with human herpes viruses (HHV), particularly HHV-6 [8].

Drug metabolites bind to cellular macromolecules such as proteins, creating covalent adducts that can serve as antigenic stimuli for the immune system $[4,6]$. Several genetic factors are believed to predispose certain individuals to this type of adverse reaction. The subset of the population that is susceptible to HSRs carries defects in drug detoxifying pathways (e.g., epoxide hydrolase), such that a greater amount of a reactive drug metabolite is produced than that which can be detoxified $[2,4,6]$. Additional genetic predispositions that render certain individuals susceptible to HSRs include human leukocyte antigen (HLA) alleles, which are part of the major histocompatibility complex (discussed by Neuman et al. [17]).

Reactivation of latent viral infections has been linked to the development of more severe HSR symptoms, particularly in the context of DIHS/DRESS. For example, HHV-6 reactivation was associated with more severe organ involvement and a prolonged course of disease in 62 of 100 DIHS patients, compared with the remaining 38 patients who did not experience HHV-6 reactivation [18]. In the same study, all five deaths and ten cases of renal failure were observed among the 62 patients with HHV-6 DNA detected in the serum [18].

HHV-6 is a lymphotropic DNA virus belonging to the Betaherpesviridae subfamily $[19,20]$. Two genetic variants of HHV-6 exist, HHV-6A and HHV-6B. While little is known about HHV-6A, HHV-6B infection often occurs during the first 2 years of life and is associated with acute febrile illness in young children and exanthem subitum in infants [1926]. HHV-6 infection can be accompanied by convulsions and febrile status epilepticus. HHV-6 has been increasingly recognized as a cause of hepatitis and liver failure, as well as increased graft rejection and consequent decreased patient survival [20-26]. The rate of infection approaches $100 \%$ in individuals 2-3 years of age [21].

Following the initial infection, HHV-6B remains present in a latent phase, and infection can be reactivated during episodes of immunosuppression [20, 22, 24, 26]. Inherited forms of both HHV-6A and HHV-6B have been shown to integrate in chromosomes. This condition, known as chromosomally integrated HHV-6 (CIHHV-6), occurs in $0.8 \%$ of control populations but is found in approximately $2 \%$ of patient populations in Europe, United States, and the United Kingdom, with a lower rate in Japan. CIHHV-6 is characterized by the complete integration of the HHV-6 genome into the host germ line genome, such that CIHHV6 DNA is found in every nucleated cell in the body [24, 27]. Persistently high viral copy numbers in whole blood or serum are observed in individuals with this condition $[28,29]$. The viral genome of CIHHV-6 is transmitted vertically in the germline in a Mendelian manner [27]. Approximately $1 \%$ of newborns are diagnosed with congenital HHV-6, all of which are infected with CIHHV-6, directly or indirectly. In a sample of 43 infants with congenital infection, the majority (86.0\%) were born with inherited CIHHV-6, while the remaining (14.0\%) were not born with CIHHV-6 but became infected with HHV-6 transplacentally from their CIHHV-6-positive mothers [30].

The cellular DNA damage machinery responds to virus infection and the foreign genomes that accumulate in the nuclei of infected cells. Many DNA viruses have been shown to manipulate the cellular DNA damage response pathways in order to create environments conducive to their own replication. Some cellular factors are activated during infection while others are inactivated [31].

Arbuckle et al. showed that HHV-6 DNA integrates specifically and efficiently into the telomere sequences of chromosomes. The integrated virus can be chemically activated with trichostatin $\mathrm{A}$, a stimulatory compound known to reactivate latent herpesviruses [32].

Active HHV-6 replication is determined by the presence of HHV-6 DNA in serum, plasma, or cerebrospinal fluid, or by reverse-transcriptase polymerase chain reaction (RTPCR) in peripheral blood mononuclear cells (PBMC). RT-PCR is the sole technique that allows active HHV-6 replication to be differentiated from inactive CIHHV-6 [33]. It is important that active HHV-6 replication is differentiated from CIHHV-6 [34]. 
The present paper reviews recently published case reports of SCAR (DIHS/DRESS and SJS/TEN) and DILI developed secondary to drug exposure, with a particular focus on the role of HHV-6 reactivation and CIHHV-6 presence in the clinical outcome of the reaction. Our principal aim is to address the role of HHV-6 reactivation in the course of HSRs, particularly in DILI and DIHS/DRESS. In addition, we will focus on the complex cellular responses triggered by HHV-6 reactivation.

\section{Materials and Methods}

Studies discussed in this paper were selected based on a PubMed search of English language papers published in the last 15 years (1997-2011) using keywords such as "HHV6 and hypersensitivity," "HHV-6 and DIHS," "HHV-6 and DRESS," "HHV-6 and SJS," "HHV-6 and TEN," "HHV6 reactivation and drug," "HHV-6 and drug rash," and "chromosomally integrated HHV-6." Case reports presented deal largely with anticonvulsants and included HHV-6 reactivation. The selected case reports are part of a larger database of HSR cases with HHV-6 reactivation. In addition, our laboratory has studied HSRs and their mechanisms for the last 25 years, and we discuss the cases based on our experience related to the laboratory and clinical manifestations.

\section{Results}

3.1. HSR and HHV-6 Reactivation. Following initial infection in early childhood, HHV-6 continues to exist in a latent phase in the body. Consequently, HHV-6 DNA can be measured in different body compartments in HHV-6-positive individuals without active infection. Trace amounts of HHV6 viral DNA were also detected by real-time quantitative PCR in $91(26.8 \%)$ of 339 pediatric patients diagnosed and treated for acute lymphoblastic leukemia [34]. Low rates of HHV-6B DNA were detected in whole blood (8.0\%), PBMCs (16.5\%), and polymorphonuclear leukocytes $(10.5 \%)$ belonging to 200 volunteers [54]. HHV-6A DNA was not observed in this sample. The mean observed HHV-6B viral loads were 81 copies $/ 10^{6}$ cells in whole blood, 62 copies $/ 10^{6}$ cells in PBMCs, and 34.5 copies $/ 10^{6}$ cells in polymorphonuclear leukocytes. Based on these findings, Géraudie et al. classify healthy individuals as having HHV-6B viral loads below 100 copies $/ 10^{6}$ cells [54]. HHV-6-DNA was positive in only $27(39.1 \%)$ blood samples from 69 children undergoing elective tonsillectomy for moderate tonsillar hyperplasia or recurrent streptococcal infection without evidence of acute HHV-6 infection, while evidence of HHV-6 DNA was found in $100 \%$ of tonsil samples in the same population [55].

The common features of DIHS identified in a sample of 7 patients were high fever $\left(\geq 39^{\circ} \mathrm{C}\right)$ in all patients, facial edema in all patients, diffuse lymphadenopathy in $5(71.4 \%)$ patients, hypereosinophilia $\left(>0.5 \times 10^{9} / \mathrm{L}\right)$ in $4(57.1 \%)$ patients, atypical circulating lymphocytes in 4 (57.1\%) patients, ALT elevated $>3$ times the reference level in 5 (71.4\%) patients, and hypogammaglobulinemia in $4(57.1 \%)$ patients [14]. The onset of DRESS took place after a mean period of 25 days (5 days-6 weeks) of therapy with the incriminated drug [14]. Similar findings are reported in other cohorts of DIHS patients $[15,56]$.

Several studies suggest that HHV-6 reactivation can only occur in susceptible individuals under conditions of transient immunosuppression, such as those transiently associated with the onset of DIHS [56, 57]. Lower serum IgG levels were observed in 10 adult anticonvulsant-induced HSR patients (mean $745 \mathrm{mg} / \mathrm{dL}$ ) compared to 15 controls $(P<0.001)$. Serum IgG levels continued to decrease for several days after the drug was discontinued [57]. Similarly, circulating levels of B cells were also decreased in DIHS patients, compared to controls [15, 57]. In susceptible individuals, continuous therapy with anticonvulsants, which have been associated with DIHS, can lead to decreases in B cells and subsequent hypogammaglobulinemia. Druginduced hypogammaglobulinemia could account for the delay between DIHS onset and HHV-6 [57]. Moreover, HHV-6 reactivation may occur at the same time, but it cannot always be detected in blood, since it takes 2-4 weeks for antibodies to appear after infection or reactivation. Because decreases in circulating IgG and B cell levels are not observed with other hypersensitivity conditions such as SJS/TEN, depressed levels of IgG and B cells can be used as biomarkers for the onset of DIHS [57].

HHV-6 reactivation may be partially explained by the immunosuppressive effects of DIHS-related drugs. The magnitude of inflammation is often proportional to the clinical manifestations, while hypogammaglobulinemia and HHV6 reactivation worsen the clinical course of the disease [58]. Hypogammaglobulinemia is thus an early symptom of severe DIHS.

A more detailed description of disease progression is presented in case reports, some of which are summarized in Table 1 [35-52]. Fever was present in all patients described in these reports. Edema, predominantly on the face, was observed with a relatively high frequency $[35,37,39$ $44,47-49,52]$, as were lymphadenopathy $[35,36,39,41-$ $43,45,46,49-51]$, hypereosinophilia [35-40, 42-52], and atypical lymphocytes $[35,36,38-40,42,44,46,47,52]$. Internal organ involvement manifested itself largely as liver dysfunction, with elevated levels of liver enzymes [35$46,48-50,52]$ and cholestatic hepatitis with hepatocellular insufficiency [51]. Kidney failure was observed in a 75year-old lamotrigine patient [51]. Multiple organ failure was observed in a couple of studies $[47,51]$, one of which resulted in death [47]. Hypogammaglobulinemia, another symptom of DIHS, was observed in a number of studies as well $[35,38,39,45,49]$.

The offensive drug is immediately interrupted in DIHS patients, and treatment with prednisolone is often used to reverse the condition [15]. Symptoms begin to improve gradually, but both fever and skin manifestations often relapse approximately 2-3 weeks after the onset of DIHS. There is a delay until antibodies to the virus are generated. Therefore, there is a delay until the peak of the infection is detected. Symptoms relapse coincides with detection of HHV-6 reactivation, measured by circulating anti-HHV- 6 antibodies and HHV-6 DNA $[15,56]$. 


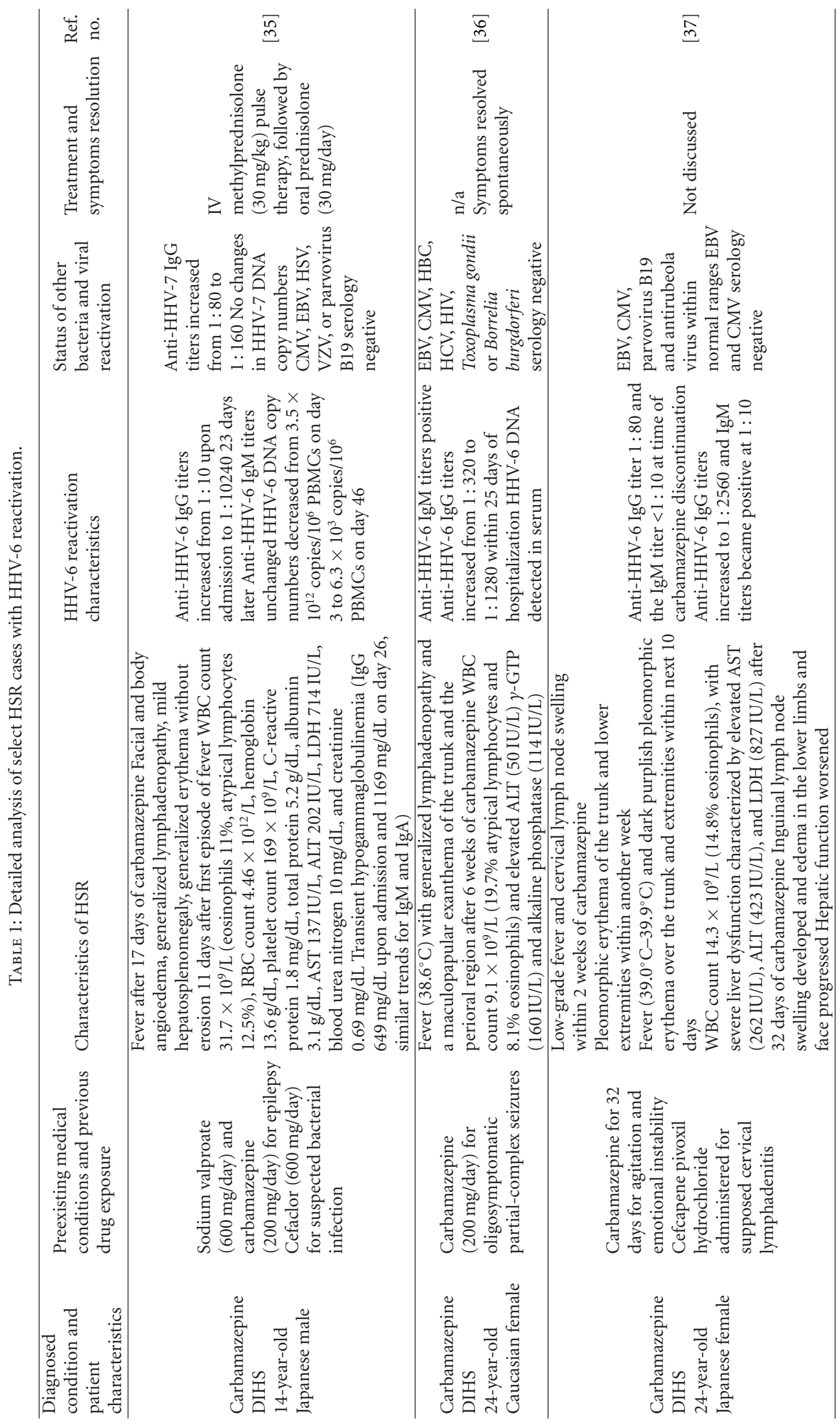




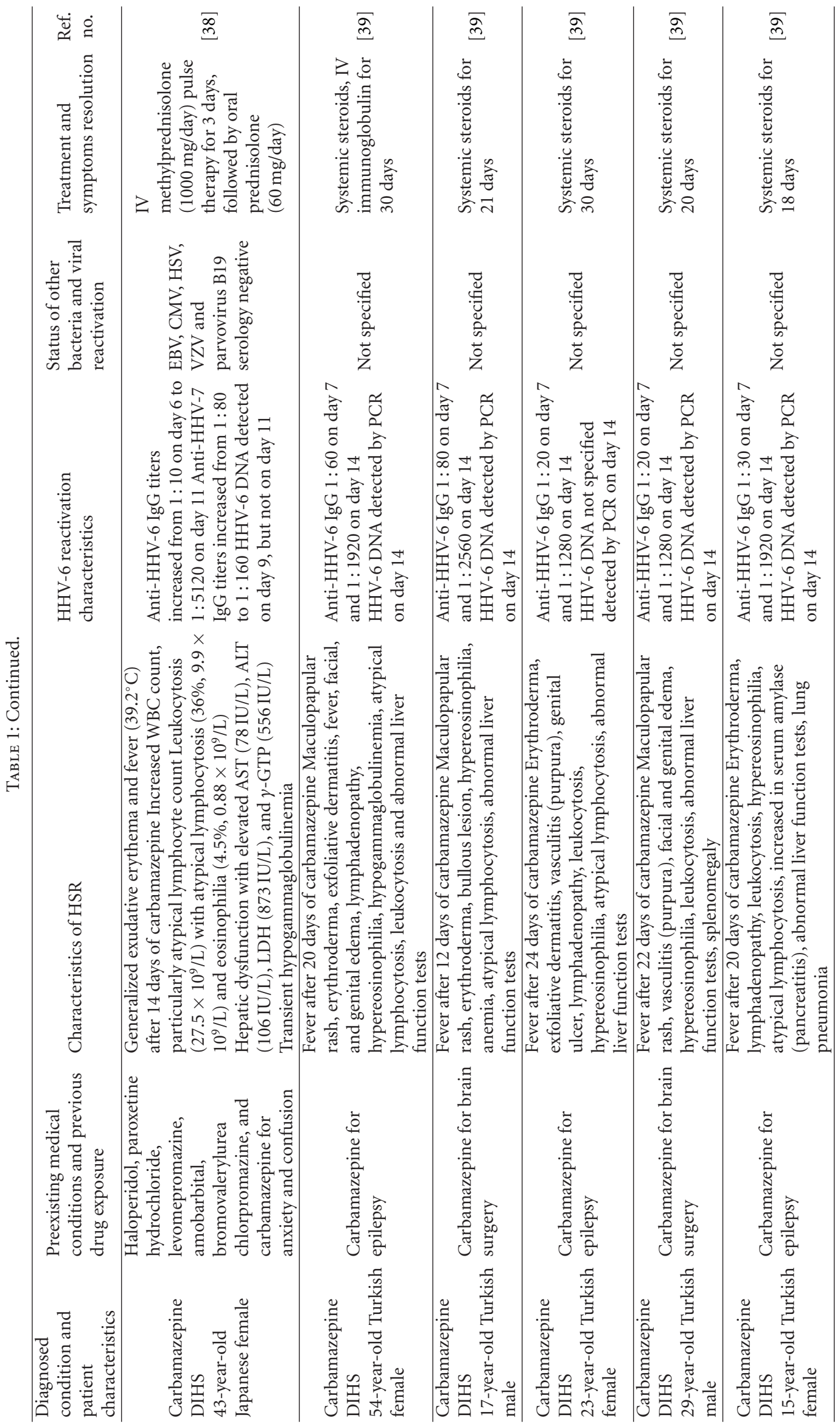



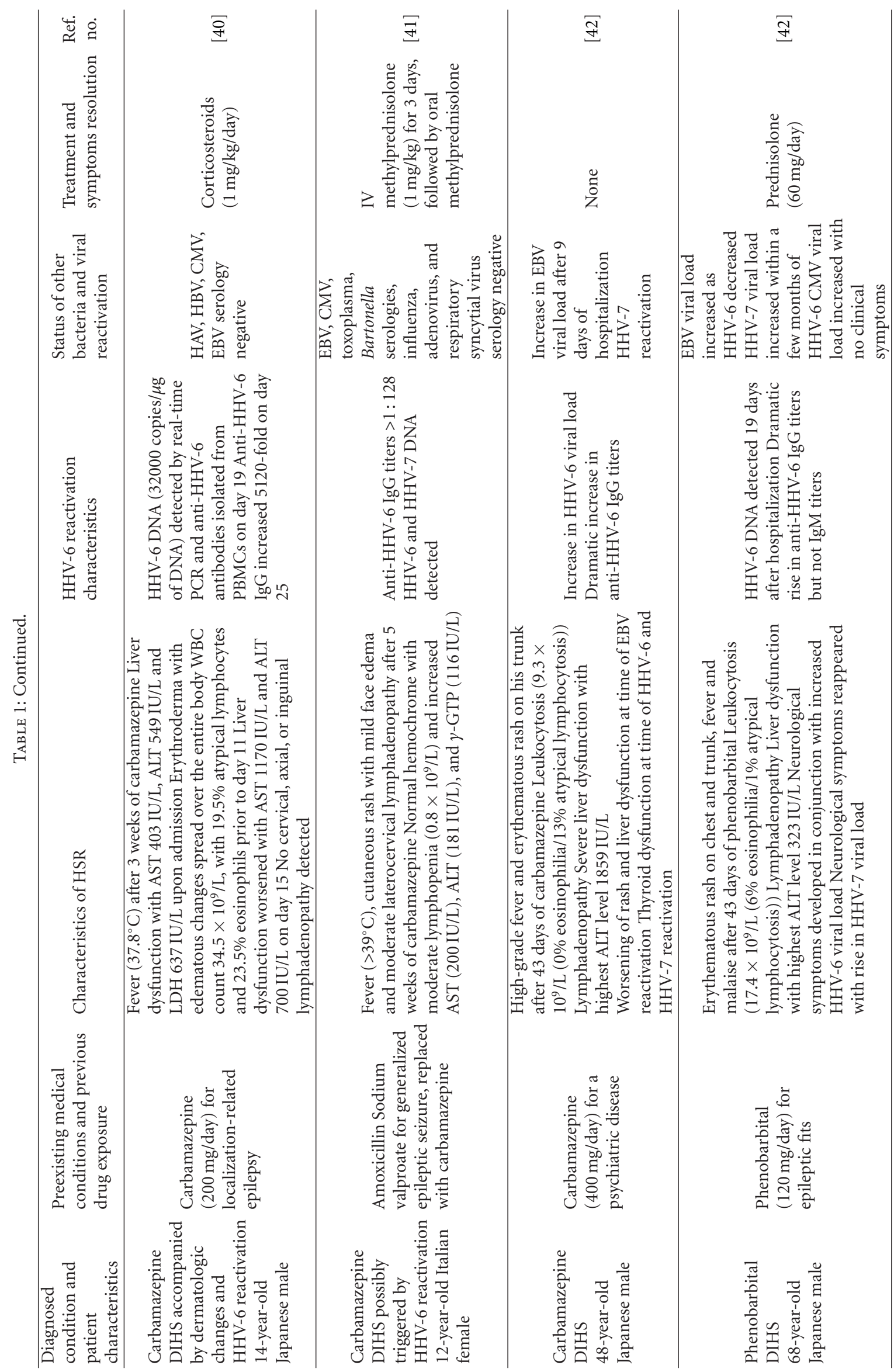


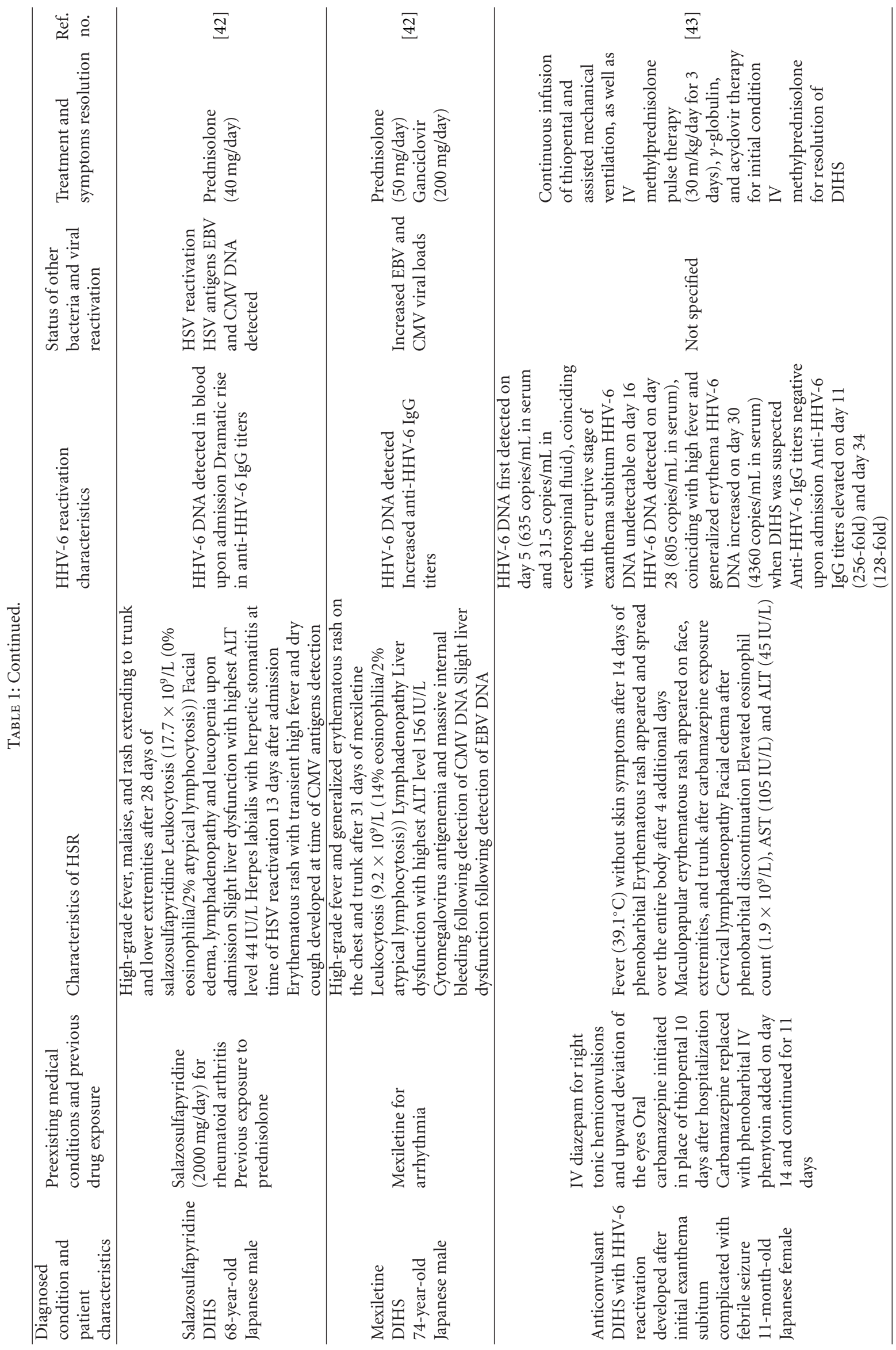




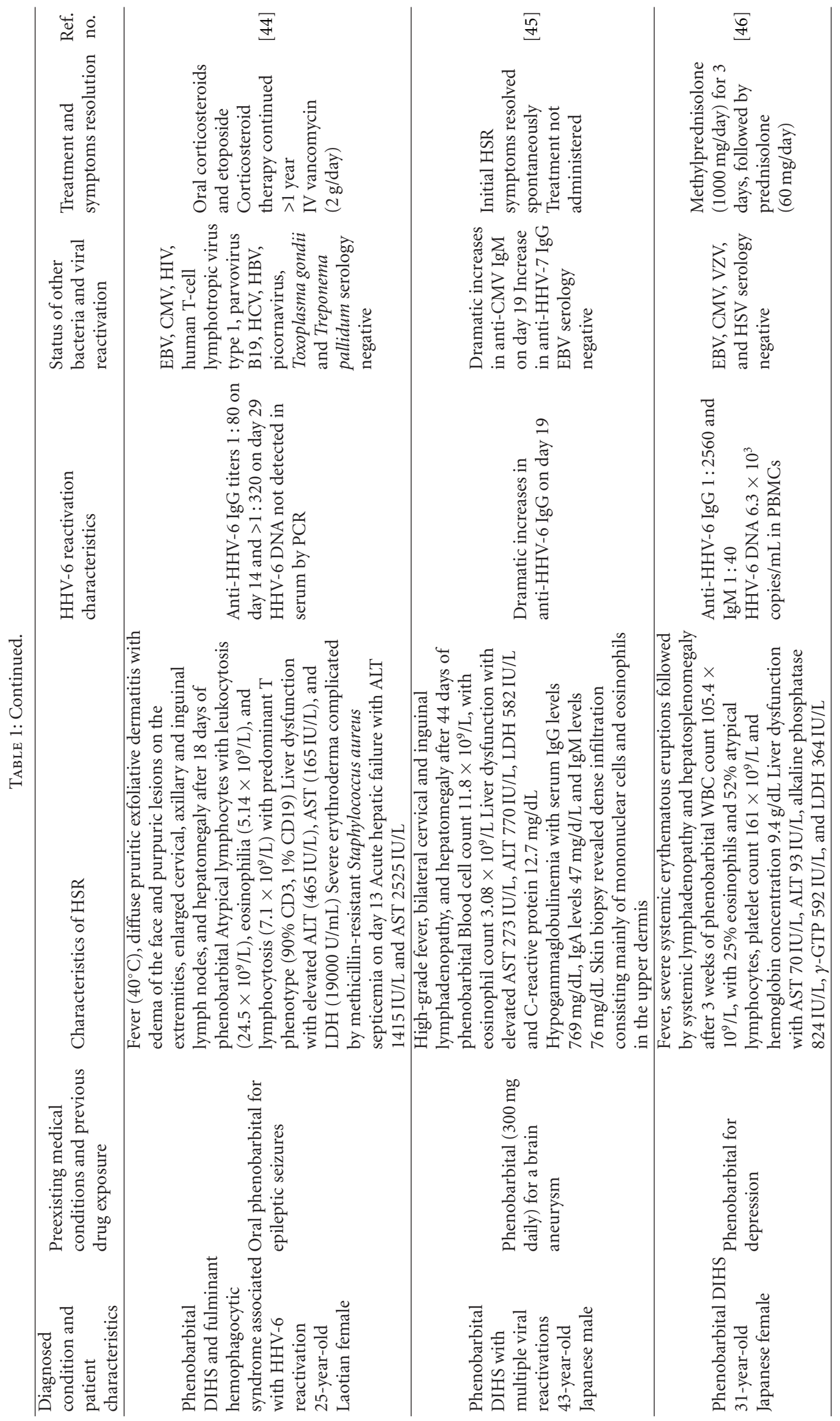




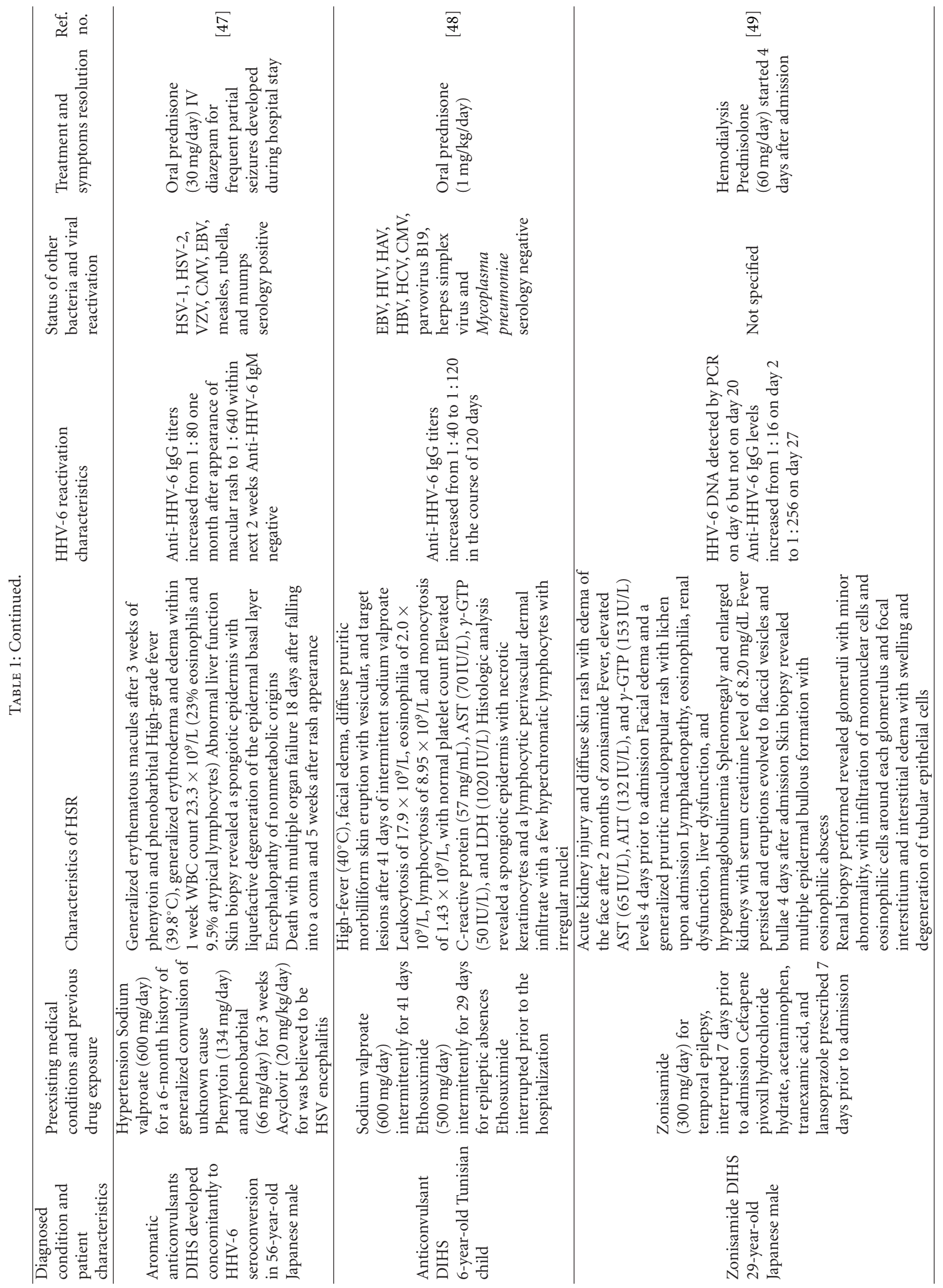




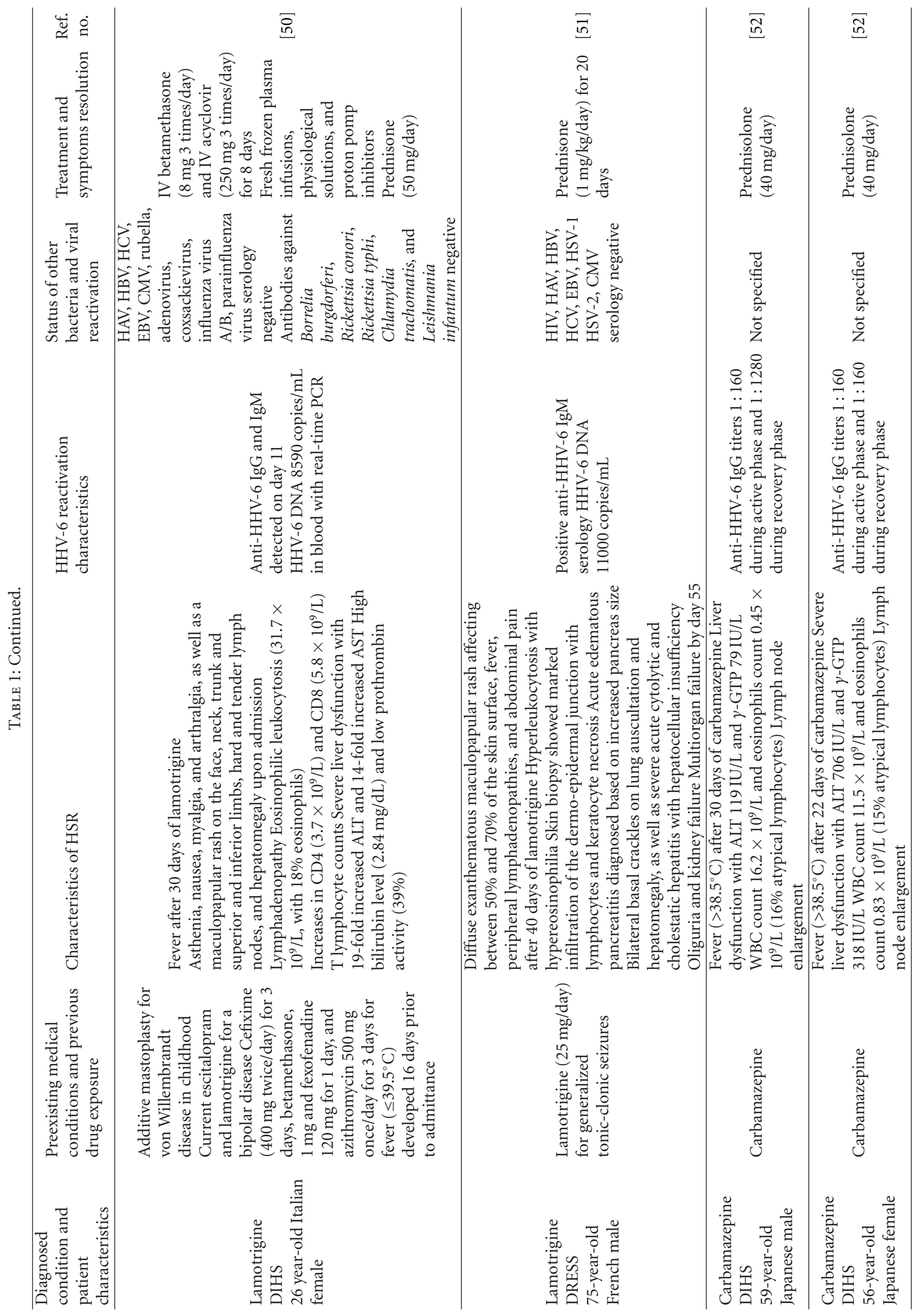




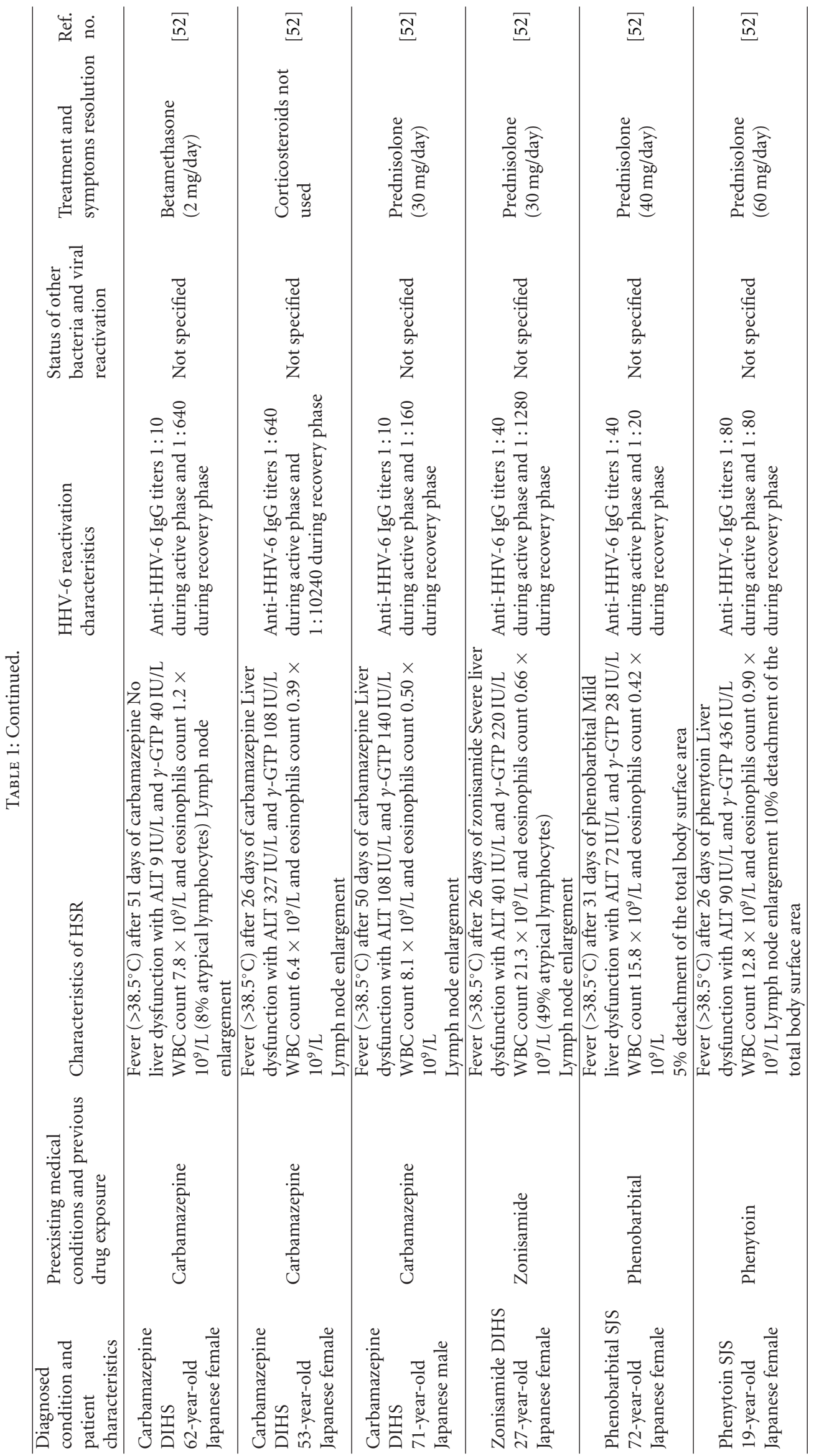




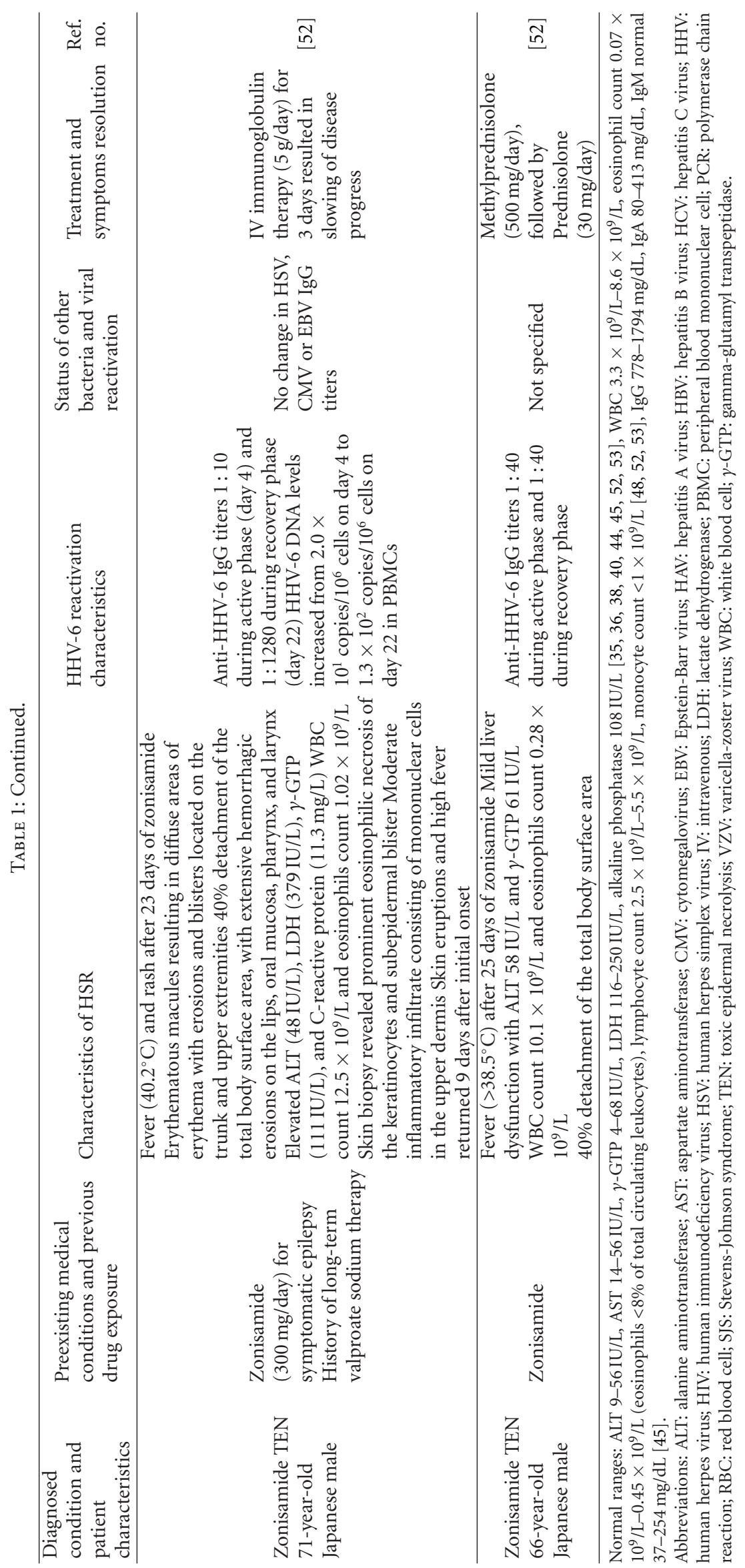


Anti-HHV-6 IgG levels are elevated after 3 weeks following the onset of the reaction (time of drug withdrawal), but not after 2 weeks $[58,59]$. Increases in HHV-6 DNA in PBMCs were found to precede the increases in anti-HHV-6 IgG levels in anticonvulsant HSR patients and were absent in controls [57]. The presence of HHV-6 DNA in PBMCs was found to correlate with the magnitude of anti-HHV-6 antibody titers $(P=0.0002)$ [60]. Intermittent detection of HHV-6 DNA in PBMCs was not indicative of illness, such that HHV-6 DNA can be found in the PBMCs at low levels in immunocompetent children, with and without symptoms [60].

Significant increases in anti-HHV-6 IgG titers were noted in all 6 patients included in a study. HHV-6 infection was confirmed in all 6 patients by PCR in PBMCs. HHV-6 reactivation was observed between 17 and 27 days after the onset of the reaction [56].

The presence of HHV-6 DNA in plasma or serum is evidence of active HHV-6 infection. In addition, the presence of serum anti-HHV-6 IgM and increases in the levels of antiHHV-6 IgG levels are used to differentiate primary HHV6 infection (i.e., seroconversion) from HHV-6 reactivation. Serum anti-HHV-6 IgG was detected in 7 DRESS patients analyzed, with serum anti-HHV-6 IgM detected in only $4(57.1 \%)$ patients. Seroconversion was diagnosed in 2 patients, in which serum anti-HHV-6 IgM titers were initially undetectable and became detectable in subsequent serum samples, coinciding with increases in anti-HHV-6 IgG titers [14]. Seroconversion is described in detail in a 56-yearold male patient with aromatic anticonvulsant-induced HSR [47].

Aside from the presentation of fever and cutaneous symptoms, other features of HHV-6 reactivation can include lymphadenopathy, hepatosplenomegaly, encephalitis caused by the virus, and severe lymphocytopenia [56] .

HHV-6 replication in hepatocytes led to severe hepatitis, associated with elevated enzyme levels, in an 18-year-old female [25]. Anti-HHV-6 antibody titers were elevated, as were HHV-6 DNA levels [25]. Higher odds of detecting HHV-6 DNA in PBMCs and liver biopsies were found in cases of fulminant hepatic failure or acute decompensation of chronic liver disease, compared to chronic liver disease $(P=0.02)$, in a sample of 23 children (median age 24 months) with acute liver failure. Similarly, higher HHV-6 DNA levels were found in cases of fulminant hepatic failure or acute decompensation of chronic liver disease, compared to chronic liver disease cases $(P=0.0043)$. These findings suggest that HHV-6 infection may cause liver failure in children [20].

Tumor necrosis factor- (TNF) $\alpha$ and interleukin- (IL) 6 levels were initially elevated prior to HHV-6 reactivation in 4 $(66.7 \%)$ of 7 patients in a study. Although initially high, IL-6 levels decreased just prior to HHV-6 reactivation. IL-6 levels were once again elevated after HHV-6 infection in 5 (83.3\%) of 6 patients [56]. IL- 6 and TNF- $\alpha$ are produced primarily by monocytes and macrophages, the likely reservoir cells of latent HHV-6. Yoshikawa et al. propose that HHV6 reactivation induces cytokine synthesis, which in turn modulate clinical manifestations [56]. These cytokines likely play an important role in viral reactivation, yet the low number of patients analyzed in this study makes a definite answer impossible [56]. Serum levels of IL-5, interferon (IFN) $-\gamma$, and eosinophil cationic protein were increased on day 29 and decreased on day 39 during an episode of carbamazepine DIHS. IL-6 was also increased at this time [58].

An interesting case of drug sensitization was observed in a patient who developed symptoms of DIHS within a few days of being exposed to the antibiotic cefaclor. This patient was previously exposed to cefaclor during an episode of carbamazepine-induced DIHS [58]. Slight increases in IL5 , IL-6, IL-10, IFN- $\gamma$, and eosinophil cationic protein were elevated in sera on day 6 of cefaclor DIHS [58]. A druginduced lymphocyte stimulation test using PBMCs showed that the patient was sensitized to carbamazepine during the first episode, but not to cefaclor. Results of the test showed sensitivity to cefaclor during the second episode [58]. During the first episode, carbamazepine-induced HSR was diagnosed 17 days after the start of carbamazepine, consistent with DIHS. Also, symptoms persisted after the drug was interrupted, and the patient responded to pulsed intravenous (IV) methylprednisolone. In contrast, the patient developed the symptoms much quicker during the second episode, during which time the symptoms were milder and disappeared faster after interruption of cefaclor. The involvement of HHV-6 during the first episode was established with anti-HHV-6 IgG titers and HHV-6 DNA. Absence of HHV6 reactivation could explain the milder symptoms during the second episode [58]. The magnitude of inflammatory cytokine increase was higher, and eosinophilia was more pronounced during the more severe carbamazepine-induced DIHS, prompting Aihara et al. to argue that HSR is mediated by both elevated inflammatory cytokine levels and activated eosinophils [58].

It is also possible that corticosteroids administered as initial treatment for drug toxicity are involved in the reactivation of HHV-6, Epstein-Barr virus (EBV), and cytomegalovirus (CMV), which became active in the later stage of the disease [15].

Anti-HHV-6 IgG titers were elevated in 7 DIHS patients 21-38 days after the onset of the reaction. Simultaneous elevation in anti-HHV-7 IgG was observed in 6 patients. An elevation in anti-CMV IgG was observed in all patients 35-54 days after the onset of the reaction. Only 2 patients experienced an elevation in anti-EBV IgG, 37 and 48 days after the onset of the reaction. Antibodies to herpes simplex virus, varicella-zoster virus, human parvovirus B19, rubella, and measles were not changed [15]. Viral DNA was detected in whole blood in all patients for whom anti-viral IgG was observed, and in serum for 6 of 7 HHV- 6 patients, 5 of 6 HHV-7 patients, and all CMV and EBV patients. Rises in CMV viral loads followed rises in HHV-6 viral loads by 10 21 days [15]. Multiple viral reactivations in a single patient are reported in another study as well [45].

HHV-6 and/or HHV-7 often reactivate first, followed by CMV and/or EBV [15]. There appears to be a correlation between relapse of symptoms and detection of increased viral loads for the virus that gets reactivated first (i.e., HHV-6 or 
HHV-7). Subsequent reactivation of CMV and EBV could be asymptomatic [15]. Further immune system perturbations brought about by the initial HHV reactivation are believed to be triggers for subsequent reactivation of other HHVs [15].

3.2. Chromosomally Integrated HHV-6. CIHHV-6 was described and quantified in healthy blood donors and various hospital populations (e.g., organ transplant recipients and immunosuppressed patients) [28, 61-67]. The mean viral loads in whole blood ranged from $10^{6}$ copies $/ \mathrm{mL}$ to $10^{7}$ copies/mL [28, 62, 64].

Vertical transmission of inherited chromosomal integration is well documented $[61,68]$. In addition, there are reports of CIHHV-6 acquisition through bone marrow transplant, followed by the presence of HHV-6 in every cell derived from hematopoietic stem cells [24, 69-71].

It is not known if CIHHV-6 can activate from its integrated state in vivo, but several lines of evidence suggest that this is a significant possibility. Integrated HHV-6 has been shown to be activated in vitro [32] using histone deacetylase inhibitors and other compounds known to reactivate herpesviruses from latency [27]. As previously discussed, transmission of CIHHV-6 from infected mothers to their non-CIHHV-6 infants, via the placenta, is another indicator that CIHHV-6 may be activated from its integrated state in vivo [30]. Children suspected of encephalitis in the United Kingdom had a four times greater rate of CIHHV6 than the general population [72], and liver transplant patients with CIHHV-6 have higher rates of graft rejections and opportunistic infections [62]. Marek's Disease virus, a herpesvirus associated with tumors in chickens, can reactivate from its integrated state in vitro [27]. If specific drugs can cause integrated virus to activate, then individuals with CIHHV-6 may be at an increased risk for drug-induced HSR.

Only a few cases of HSR in CIHHV-6 patients have been reported. Watanabe et al. report the case of a 47year-old Japanese male with fever $\left(38.8^{\circ} \mathrm{C}\right)$ and generalized erythematous rash 78 days after carbamazepine exposure [73]. Mild hepatotoxicity (ALT $70 \mathrm{IU} / \mathrm{L}$, AST $73 \mathrm{IU} / \mathrm{L}, \gamma$ glutamyl transpeptidase $129 \mathrm{IU} / \mathrm{L}$, and lactate dehydrogenase $686 \mathrm{U} / \mathrm{L}$ ) and hypogammaglobulinemia (IgG $609 \mathrm{mg} / \mathrm{dL}$, IgA $34 \mathrm{mg} / \mathrm{dL}$ and IgM $27 \mathrm{mg} / \mathrm{dL}$ ) were measured. An abdominal skin biopsy revealed hydropic and vacuolar degeneration of epidermal basal cells, lymphocytic infiltration in the epidermis, and a dense upper dermal infiltrate consisting mainly of mononuclear cells [73]. Anti-HHV-6 IgG titers were increased 128-fold 6 weeks after the reaction onset, while anti-HHV-6 IgM titers remained unchanged throughout the course of the reaction, pointing towards HHV-6 reactivation. HHV-6 DNA was persistently high in serum (>10000 copies/mL) and whole blood. Fluorescent in situ hybridization revealed CIHHV-6 on chromosome 1q44 [73].

HHV-6 DNA levels in primary infection and acute reactivation are typically below $5.5 \times 10^{5}$ copies [27]. Of interest, the only cases reported of viral loads above this level (or in the same range as individuals with CIHHV-6) appear to be those with graft-versus-host disease or DIHS, two conditions that have very similar symptoms and courses $[18,27,74]$.

\section{Discussion}

In the present paper, we review cases of HSR associated with $\mathrm{HHV}-6$ reactivation. In the vast majority of patients, HHV-6 infection occurs during infancy or early childhood [60]. Following resolution of the primary infection, the virus remains latent in salivary glands, PBMCs, and the central nervous system. HHV-6 reactivates in immunosuppressed individuals and is associated with fever, rash, encephalitis, bone marrow suppression, and transplanted organ rejection. Primary HHV-6 infection can be identified by the presence of HHV-6 DNA in the serum, plasma, or cerebrospinal fluid, or reverse transcription PCR in the absence of elevated antibody titers [60]. Reactivation is marked by detection of both viral DNA and elevated anti-HHV-6 antibody titers [60]. As antiHHV-6 IgG levels increase during the course of the reaction, anti-HHV-6 IgM levels remain constant around $<1: 20$ in patients with HHV-6 reactivation $[42,75]$.

HSRs seem to occur with almost a thousandfold higher incidence in AIDS patients compared to immunocompetent individuals exposed to the same medication, as there is a much higher exposure to drugs in these patients, as well as a much higher incidence of viral infections [76, 77]. Aside from a higher incidence of HSR, HIV positivity can also lead to more severe symptoms, compared to HIVnegative patients [77]. In addition, an in vitro study showed increased DNA viral replication in PBMCs belonging to DIHS patients that were depleted for natural killer cells (NK) [78]. These findings point toward an extensive immune barrier aimed against DIHS development, while immune defects in components of these pathways can explain why only a relatively small amount of the population exposed to a drug will develop the reaction.

Interestingly, Kano et al. suggest that $\mathrm{HHV}-6$ reactivation is not a consequence, but rather a prerequisite for anticonvulsant HSR [57]. The expansion of CD $4^{+} \mathrm{T}$ cells and $\mathrm{CD}^{+} \mathrm{T}$ cells in response to $\mathrm{HHV}-6$ reactivation seems to be of extreme importance in the development of multiple organ failure during the course of anticonvulsant HSR. From their immunological findings, Kano et al. believe that continuous anticonvulsant therapy leads to transient immune dysfunction, marked by decreased IgG production [57]. While $\mathrm{T}$ cells protect against reactivation of viruses from a latent stage, antibodies prevent the dissemination of reactivating lytic virus. Therefore, DIHS may occur when transient drops in B cell counts and immunoglobulin production allow HHV-6 to be reactivated from latency, in conjunction with the presence of drug-specific $\mathrm{T}$ cells. The likely explanation for the lag between start of anticonvulsant therapy and onset of disease is that time is required for immunoglobulin levels to drop below a certain threshold [57].

An in vitro study using the human T cell line MT4 found that therapeutic doses of both sodium valproate and carbamazepine led to enhanced HHV-6B replication in a doseindependent manner, whereas phenytoin and sulfasalazine 
had no effects on HHV-6B replication or cell proliferation [79]. In vivo, there have been reports of phenytoin and sulfonamide antibiotics leading to HHV-6 reactivation in DIHS patients [42, 43, 47, 52].

As such, while widespread, HHV-6 infection is not encountered in all DIHS cases. For example, HHV-6 DNA was detected by PCR in blood or serum in a 25 -year-old female treated with phenobarbital, while it was absent in a 21-year-old female treated with phenytoin [16]. Matsuda et al. describe 2 cases of carbamazepine-induced DIHS in which no viral reactivation was observed [53]. Symptoms, including fever, skin eruptions, and liver involvement, occurred between 22 days and 4 weeks after carbamazepine initiation in the two patients, which is consistent with DIHS. Furthermore, eosinophilia and a drop in white blood cell count were observed in both patients [53].

HHV-6 reactivation typically occurs 2-3 weeks after the development of rash in DIHS patients $[8,76]$. Evidence of this are elevated HHV-6 IgG titers and plasma HHV-6 DNA [76]. HHV-6 reactivation is often accompanied by relapse of fever and hepatitis [8]. A cascade of viral reactivation can then be started, with HHV-6, EBV, and/or HHV-7 at the top, followed, with some delay, by other herpes viruses, particularly CMV. Reactivation of these viruses is followed by development or exacerbation of clinical symptoms of DIHS, including various organ failures $[8,76,80]$. Of particular interest is CMV reactivation, which can be followed by transient fever, skin rash, myocarditis, pneumonia, or gastrointestinal bleeding [8].

Clinical symptoms (fever, hepatitis, and/or skin rash) correspond to the appearance of detectable HHV-6 DNA levels. Fever and/or hepatitis are the most common clinical features of HHV-6 reactivation in DIHS patients. Based on these findings, HHV-6 reactivation leads to a more severe course of disease in patients with DIHS [18]. HHV6 reactivation is associated with more severe organ involvement and a prolonged course of the disease in patients with drug rash and systemic symptoms, compared with the remaining patients who did not experience HHV-6 reactivation [18]. Significant detection of HHV-6 DNA corresponds to the presence of anti-HHV-6 IgG titers, and there is a positive correlation between HHV-6 DNA detection and the development of fever and hepatitis [18].

While HHV-6 reactivation is a common feature of DIHS/DRESS, HHV-6 DNA was not detected in 15 patients with generalized morbilliform/maculopapular drug reactions [81]. HHV-7, CMV, or EBV DNA was not detected in any of the patients included in this study. In situ hybridization revealed HHV-6 mRNA in a small subset of infiltrating mononuclear cells around blood vessels and appendages in DIHS patients only [81]. Similarly, only $1(25.0 \%)$ of 4 SIS/TEN patients for whom data was available showed an increase in anti-HHV-6 IgG titers from $1: 10$ to $1: 1280$ [52]. Aside from a lower likelihood of HHV-6 reactivation, SJS/TEN is marked by a quicker onset of reaction than DIHS/DRESS (2-3 weeks versus a mean 34 days) [52]. However, fever $\left(>38.5^{\circ} \mathrm{C}\right)$, leukocytosis, eosinophilia, and atypical lymphocytosis were common features of both SJS/TEN and DIHS/DRESS, whereas liver dysfunction was observed predominantly in SJS/TEN patients and lymph node enlargement was observed predominantly in DIHS/DRESS patients. Treatments for SJS/TEN included systemic corticosteroids in $7(87.5 \%)$ patients and IV immunoglobulin in $1(12.5 \%)$ patient [52].

Furthermore, Teraki et al. warn that some of the clinical features of anticonvulsant-induced SJS/TEN may differ from SJS/TEN induced by other drugs, such as a more delayed onset of symptoms in the former category [52]. Additionally, the rate of hepatic dysfunction and hematological anomalies was also higher than that described with SJS/TEN induced by other drugs [52]. HHV-6 reactivation and atypical lymphocytosis were observed in DIHS patients predominantly, compared to SJS/TEN patients. The precise morphological nature of the skin reaction is another criterion used to differentiate DIHS from SJS/TEN. These findings should be interpreted with care due to the low sample size [52].

Carbamazepine was associated with $12(52.2 \%)$ of 23 anticonvulsant HSR cases reported in a cohort study. All patients developed fever and pruritus. Maculopapular exanthematous eruptions were observed in 15 patients, erythroderma in 11 patients, exfoliative dermatitis in 3 patients, bullous eruption in 1 patients, urticaria in 1 patient, and purpura (vasculitis) in 2 patients [39]. There was no relationship between the drug used and the length or severity of the reaction. In addition to the skin, $20(87.0 \%)$ patients had at least one other organ affected by the reaction, while $8(34.8 \%)$ patients had at least two other organs affected by the reaction. DILI was observed in $12(52.2 \%)$ patients, and kidney involvement was observed in $8(34.8 \%)$ patients. Other affected organs include the spleen (splenomegaly), the lung, the thyroid (hypothyroidism), the heart, and the pancreas [39].

Drug-drug interactions are particularly problematic when several pharmaceutical agents capable of inducting HSR are administered simultaneously. For example, Conilleau et al. report the case of a child exposed intermittently to two anticonvulsants prior to developing DIHS [48]. Despite ethosuximide being interrupted prior to hospitalization and sodium valproate being associated more often with DIHS, it appears that the reaction was caused by the combination of these two structurally unrelated anticovulsants, as a patch test was positive for both ethosuximide and sodium valproate [48]. In a separate case, an infant that was exposed to carbamazepine, phenytoin, and phenobarbital presented with initial HHV-6 infection. Despite the patient being diagnosed with phenobarbital hypersensitivity [43], all three of these aromatic antiepileptic drugs have the potential to cause HSR [2]. Our group also describes patients susceptible to multiple antiepileptics [17].

Minocycline-induced DIHS with EBV reactivation was reported in a 24-year-old African American female. The presence of HHV-6 was not assessed in this study [82]. HHV6 reactivation was observed in two patients with sulfasalazine severe hypersensitivity [83]. Sequential activation of HHV6, HHV-7, herpes simplex virus, and CMV was observed in a 46-year-old male who developed DIHS after being exposed to cyanamide, a drug used to control alcoholism [84]. HHV-6 reactivation was observed in 2 elderly patients 
with allopurinol DIHS [26, 79], and EBV reactivation was observed in a 40-year-old black male with allopurinol DIHS and pancreatitis [85]. The cause of the reaction was unknown in an 18-year-old female with SJS/TEN exposed to valacyclovir, promethazine, synthroid, belladonna, and orthotricycline [26]. Cacoub et al. provide a comprehensive list of 44 drugs associated with DIHS/DRESS [7].

In addition to anticonvulsants, patients can be exposed to additional medication for the treatment of comorbid diseases, opportunistic infections, or even for the management of HSR symptoms (e.g., antibiotics or nonsteroidal inflammatory drugs administered for the treatment of fever). Furthermore, epilepsy patients are often exposed to more than one anticonvulsant, most of which are capable of causing an HSR. While medication is interrupted at the time of HSR diagnosis and the patient is encouraged to avoid rechallenge with the drug that was deemed to have initiated the reaction, it is still important that all medication is considered and tested individually for its capacity to initiate an HSR. Investigators seldom check to see if there is an additive effect between the incriminated anticonvulsant and other medication, or if the anticonvulsant caused the reaction on its own. Also, it is unlikely that HHV-6 reactivation is measured upon admission. As a result, it is difficult to establish whether the drug or the virus initiates the reaction. Kano et al. argue that HHV-6 reactivation creates an environment that favors DIHS development [57]. The same investigators report the case of a 46-year-old woman who developed DIHS 4.5 months after initiating therapy with zonisamide and corticosteroids [80]. Since the reaction occurred well outside the time frame characteristic of DIHS and since reactivation of herpes viruses was not measured, it is possible that this phenomenon could have created the conditions necessary for DIHS to occur in this patient with long-term exposure to anticonvulsant therapy [80].

The presence of proinflammatory cytokines during DILI and SCAR is supported by findings that a significantly higher number of eosinophils was found both in the blood and tissue of patients with a drug-induced maculopapular exanthems, compared to control subjects with normal skin and skin from patients with psoriasis [86]. Furthermore, viral antigens can increase recruitment of eosinophils [87].

The presence of HLA-A*3101 allele and homozygosity for epoxide hydrolase 1 (EPHX1) single nucleotide polymorphism rs1051740 (T-C) in exon 3, associated with modifications in epoxide hydrolase activity, were found in a patient with anticonvulsant HSR, possibly triggered by HHV reactivation, suggesting a genetic predisposition to HSR upon HHV reactivation [41].

HHV-6 reactivation can be further observed in the absence of an HSR and is primarily associated with hepatotoxicity. Phillips et al. were able to show with the help of transmission electron microscopy that full and empty virus capsids accumulate in the nucleus of hepatocytes, while viral particles bud out into the nuclear envelope and the cytoplasm [19]. Over the years, several drugs were used to treat HHV reactivations per se, as well as opportunistic infections in HSR patients with HHV reactivation, including idoxuridine [88], cytarabine [89], and vidarabine [90]. More recently, ganciclovir was used in a patient with HHV-6 and CMV reactivations [42]. Vancomycin was used to treat an opportunistic infection with Staphylococcus aureus in a DIHS patient with HHV-6 reactivation [44]. However, treatment against HHV-6 reactivation is often withheld out of fear of worsening the condition due to an increasing number of drugs that the patient is exposed to [26].

Drug-induced adverse reactions represent a concern for patients, clinicians, the pharmaceutical industry, and health providers. Interestingly, very little mention of $\mathrm{HHV}$ 6 reactivation is made in a comprehensive article discussing DILI, including acute liver failure in major DILI registries from Europe and the United States [91].

In conclusion, this paper provides a multifaceted assessment of drugs implicated in HSR that have been reported to induce HHV-6 reactivation. This information may facilitate the possible link between the diagnosis of SCAR and DILI, and HHV- 6 reactivation.

\section{Abbreviations}

$\begin{array}{ll}\text { ADR: } & \text { Adverse drug reaction } \\ \text { ALT: } & \text { Alanine aminotransferase } \\ \text { AST: } & \text { Aspartate aminotransferase } \\ \text { CIHHV-6: } & \text { Chromosomally integrated human herpes } \\ & \text { virus-6 } \\ \text { CMV: } & \text { Cytomegalovirus } \\ \text { DIHS: } & \text { Drug-induced hypersensitivity syndrome } \\ \text { DILI: } & \text { Drug-induced liver injury } \\ \text { DRESS: } & \text { Drug reaction with eosinophilia and } \\ & \text { systemic symptom } \\ \text { EBV: } & \text { Epstein-Barr virus } \\ \text { HAV: } & \text { Hepatitis A virus } \\ \text { HBV: } & \text { Hepatitis B virus } \\ \text { HCV: } & \text { Hepatitis C virus } \\ \text { HHV: } & \text { Human herpes virus } \\ \text { HIV: } & \text { Human immunodeficiency virus } \\ \text { HLA: } & \text { Human leukocyte antigen } \\ \text { HSR: } & \text { Hypersensitivity reaction } \\ \text { HSV: } & \text { Human herpes simplex virus } \\ \text { IFN: } & \text { Interferon } \\ \text { IL: } & \text { Interleukin } \\ \text { IV: } & \text { Intravenous } \\ \text { LDH: } & \text { Lactate dehydrogenase } \\ \text { PBMC: } & \text { Peripheral blood mononuclear cell } \\ \text { PCR: } & \text { Polymerase chain reaction } \\ \text { SCAR: } & \text { Severe cutaneous adverse reactions } \\ \text { SIS: } & \text { Stevens-Johnson syndrome } \\ \text { TEN: } & \text { Toxic epidermal necrolysis } \\ \text { TNF: } & \text { Tumor necrosis factor } \\ \text { VZV: } & \text { Varicella-zoster virus } \\ \text { y-GTP: } & \text { Gamma-glutamyl transpeptidase. } \\ & \\ & \end{array}$

\section{Authors' Contribution}

J. C. Pritchett and R. M. Nanau contributed an equal amount of work. 


\section{Acknowledgments}

This work was performed at In Vitro Drug Safety and Biotechnology and the HHV-6 Foundation. The authors are thankful to Kristin Loomis from the HHV-6 Foundation for her comments and editorial help.

\section{References}

[1] H. J. Zimmerman, “The spectrum of hepatotoxicity," Perspectives in Biology and Medicine, vol. 12, no. 1, pp. 135-161, 1968.

[2] N. H. Shear, S. P. Spielberg, M. Cannon, and M. Miller, "Anticonvulsant hypersensitivity syndrome. In vitro assessment of risk," Journal of Clinical Investigation, vol. 82, no. 6, pp. 1826$1832,1988$.

[3] H. J. Zimmerman, Hepatotoxicity: The Adverse Effects of Drugs and Other Chemicals on the Liver, Lippincott Williams and Wilkins, Philadelphia, Pa, USA, 2nd edition, 1999.

[4] M. G. Neuman, I. M. Malkiewicz, and N. H. Shear, "A novel lymphocyte toxicity assay to assess drug hypersensitivity syndromes," Clinical Biochemistry, vol. 33, no. 7, pp. 517-524, 2000.

[5] M. G. Neuman and M. Nicar, "Ibuprophen-induced toxic epidermal necrolysis," Translational Research, vol. 149, pp. 254259, 2007.

[6] R. M. Nanau and M. G. Neuman, "Ibuprofen-induced hypersensitivity syndrome," Translational Research, vol. 155, no. 6, pp. 275-293, 2010.

[7] P. Cacoub, P. Musette, V. Descamps et al., "The DRESS syndrome: a literature review," American Journal of Medicine, vol. 124, no. 7, pp. 588-597, 2011.

[8] M. Tohyama and K. Hashimoto, "New aspects of druginduced hypersensitivity syndrome," Journal of Dermatology, vol. 38, no. 3, pp. 222-228, 2011.

[9] H. Assier, S. Bastuji-Garin, J. Revuz, and J. C. Roujeau, "Erythema multiforme with mucous membrane involvement and Stevens-Johnson syndrome are clinically different disorders with distinct causes," Archives of Dermatology, vol. 131, no. 5, pp. 539-543, 1995.

[10] J. C. Roujeau, J. P. Kelly, L. Naldi et al., "Medication use and the risk of Stevens-Johnson syndrome or toxic epidermal necrolysis," New England Journal of Medicine, vol. 333, no. 24, pp. 1600-1607, 1995.

[11] M. Mockenhaupt, C. Viboud, A. Dunant et al., "StevensJohnson syndrome and toxic epidermal necrolysis: assessment of medication risks with emphasis on recently marketed drugs. The EuroSCAR-study," Journal of Investigative Dermatology, vol. 128, no. 1, pp. 35-44, 2008.

[12] H. J. Zimmerman, "Drug-induced liver disease," in Hepatotoxicity: The Adverse Effects of Drugs and Other Chemicals on the Liver, pp. 353-365, Appleton-Century-Crofts, New York, NY, USA, 1st edition, 1978.

[13] A. Reuben, "Hy’s law," Hepatology, vol. 39, pp. 574-578, 2004.

[14] V. Descamps, A. Valance, C. Edlinger et al., "Association of human herpesvirus 6 infection with drug reaction with eosinophilia and systemic symptoms," Archives of Dermatology, vol. 137, no. 3, pp. 301-304, 2001.

[15] M. Seishima, S. Yamanaka, T. Fujisawa, M. Tohyama, and K. Hashimoto, "Reactivation of human herpesvirus (HHV) family members other than HHV-6 in drug-induced hypersensitivity syndrome," British Journal of Dermatology, vol. 155, no. 2, pp. 344-349, 2006.
[16] M. Eshki, L. Allanore, P. Musette et al., "Twelve-year analysis of severe cases of drug reaction with eosinophilia and systemic symptoms: a cause of unpredictable multiorgan failure," Archives of Dermatology, vol. 145, no. 1, pp. 67-72, 2009.

[17] M. G. Neuman, L Cohen, R. M. Nanau, and P. A. Hwang, "Genetic and immune predictors for hypersensitivity syndrome to antiepileptic drugs," Translational Research, vol. 159, no. 5, pp. 397-406, 2012.

[18] M. Tohyama, K. Hashimoto, M. Yasukawa et al., "Association of human herpesvirus 6 reactivation with the flaring and severity of drug-induced hypersensitivity syndrome," British Journal of Dermatology, vol. 157, no. 5, pp. 934-940, 2007.

[19] M. J. Phillips, S. Poucell, J. Patterson, and P. Valencia, The Liver: An Atlas and Text of Ultrastructural Pathology, Raven Press, New York, NY, USA, 1987.

[20] L. Chevret, D. Boutolleau, N. Halimi-Idri et al., "Human herpesvirus-6 infection: a prospective study evaluating HHV6 DNA levels in liver from children with acute liver failure," Journal of Medical Virology, vol. 80, no. 6, pp. 1051-1057, 2008.

[21] M. T. Caserta and C. B. Hall, "A practitioner's guide to human herpesvirus-6 (HHV-6) and human herpesvirus-7 (HHV-7)," AIDS Patient Care and STDs, vol. 12, no. 11, pp. 833-842, 1998.

[22] A. Yagami, T. Yoshikawa, Y. Asano, S. Koie, T. Shiohara, and K. Matsunaga, "Drug-induced hypersensitivity syndrome due to mexiletine hydrochloride associated with reactivation of human herpesvirus 7," Dermatology, vol. 213, no. 4, pp. 341344, 2006.

[23] T. Yoshikawa, "Human herpesvirus 6 causes hepatitis in transplant recipients," Internal Medicine, vol. 45, no. 7, pp. 417-418, 2006.

[24] D. A. Clark and K. N. Ward, "Importance of chromosomally integrated HHV-6A and -6B in the diagnosis of active HHV-6 infection," Herpes, vol. 15, no. 2, pp. 28-32, 2008.

[25] P. Grima, R. Chiavaroli, P. Calabrese, P. Tundo, and P. Grima, "Severe hepatitis with autoimmune features following a HHV6: a case report," Cases Journal, vol. 1, p. 110, 2008.

[26] A. F. Peppercorn, M. B. Miller, D. Fitzgerald, D. J. Weber, P. A. Groben, and B. A. Cairns, "High-level human herpesvirus-6 viremia associated with onset of Stevens-Johnson syndrome: report of two cases," Journal of Burn Care and Research, vol. 31, no. 2, pp. 365-368, 2010.

[27] P. E. Pellett, D. V. Ablashi, P. F. Ambros et al., "Chromosomally integrated human herpesvirus 6: questions and answers," Reviews in Medical Virology. In press.

[28] N. L. Hoe, P. W. Tuke, R. S. Tedder et al., "The prevalence of chromosomally integrated human herpesvirus 6 genomes in the blood of UK blood donors," Journal of Medical Virology, vol. 79, no. 1, pp. 45-51, 2007.

[29] H. Jeulin, M. Guéry, L. Clément et al., "Chromosomally integrated HHV-6: slow decrease of HHV-6 viral load after hematopoietic stem-cell transplantation," Transplantation, vol. 88, no. 9, pp. 1142-1143, 2009.

[30] C. Hall, M. T. Caserta, K. Schnabel et al., "Chromosomal integration of human herpesvirus 6 is the major mode of congenital human herpesvirus 6 infection," Pediatrics, vol. 122, no. 3, pp. 513-520, 2008.

[31] G. T. Melroe, N. A. DeLuca, and D. M. Knipe, "Herpes simplex virus 1 has multiple mechanisms for blocking virus-induced interferon production," Journal of Virology, vol. 78, no. 16, pp. 8411-8420, 2004.

[32] J. H. Arbuckle, M. M. Medveczky, J. Luka et al., "The latent human herpesvirus-6A genome specifically integrates in telomeres of human chromosomes in vivo and in vitro," 
Proceedings of the National Academy of Sciences of the United States of America, vol. 107, no. 12, pp. 5563-5568, 2010.

[33] M. T. Caserta, C. B. Hall, K. Schnabel et al., "Diagnostic assays for active infection with human herpesvirus 6 (HHV6)," Journal of Clinical Virology, vol. 48, no. 1, pp. 55-57, 2010.

[34] P. Hubacek, K. Muzikova, A. Hrdlickova et al., "Prevalence of HHV-6 integrated chromosomally among children treated for acute lymphoblastic or myeloid leukemia in the Czech Republic," Journal of Medical Virology, vol. 81, no. 2, pp. 258263, 2009.

[35] Y. Aihara, S. I. Ito, Y. Kobayashi, Y. Yamakawa, M. Aihara, and S. Yokota, "Carbamazepine-induced hypersensitivity syndrome associated with transient hypogammaglobulinaemia and reactivation of human herpesvirus 6 infection demonstrated by real-time quantitative polymerase chain reaction," British Journal of Dermatology, vol. 149, no. 1, pp. 165-169, 2003.

[36] A. Zeller, N. Schaub, I. Steffen, E. Battegay, H. H. Hirsch, and A. J. Bircher, "Drug hypersensitivity syndrome to carbamazepine and human herpes virus 6 infection: case report and literature review," Infection, vol. 31, no. 4, pp. 254-256, 2003.

[37] T. Ogihara, T. Takahashi, T. Hanihara, N. Amano, and K. Matsumoto, "Carbamazepine-Induced Hypersensitivity Syndrome Associated with Human Herpesvirus 6 Reactivation [10]," Journal of Clinical Psychopharmacology, vol. 24, no. 1, pp. 105-106, 2004.

[38] H. Nakashima, K. Yamane, H. Ihn et al., "Drug-induced hypersensitivity syndrome associated with transient hypogammaglobulinaemia and increase in serum IgE level," Dermatology, vol. 210, no. 4, pp. 349-352, 2005.

[39] T. Oskay, A. Karademir, and Ö. I. Ertürk, "Association of anticonvulsant hypersensitivity syndrome with Herpesvirus 6, 7," Epilepsy Research, vol. 70, no. 1, pp. 27-40, 2006.

[40] Y. Suzuki, M. Fukuda, M. Tohyama, M. Ishikawa, M. Yasukawa, and E. Ishii, "Carbamazepine-induced drug-induced hypersensitivity syndrome in a 14-year-old Japanese boy," Epilepsia, vol. 49, no. 12, pp. 2118-2121, 2008.

[41] L. Calligaris, G. Stocco, S. De Iudicibus et al., "Carbamazepine hypersensitivity syndrome triggered by a human herpes virus reactivation in a genetically predisposed patient," International Archives of Allergy and Immunology, vol. 149, no. 2, pp. 173177, 2009.

[42] Y. Kano, K. Hiraharas, K. Sakuma, and T. Shiohara, "Several herpesviruses can reactivate in a severe drug-induced multiorgan reaction in the same sequential order as in graft-versushost disease," British Journal of Dermatology, vol. 155, no. 2, pp. 301-306, 2006

[43] S. Saida, A. Yoshida, R. Tanaka et al., "A case of drug-induced hypersensitivity syndrome-like symptoms following HHV-6 encephalopathy," Allergology International, vol. 59, no. 1, pp. 83-876, 2010.

[44] V. Descamps, F. Bouscarat, S. Laglenne et al., "Human herpesvirus 6 infection associated with anticonvulsant hypersensitivity syndrome and reactive haemophagocytic syndrome," British Journal of Dermatology, vol. 137, no. 4, pp. 605-608, 1997.

[45] Y. Kano and T. Shiohara, "Sequential reactivation of herpesvirus in drug-induced hypersensitivity syndrome [7]," Acta Dermato-Venereologica, vol. 84, no. 6, pp. 484-485, 2004.

[46] T. Nakazato, K. Suzuki, A. Mihara, Y. Sanada, Y. Aisa, and T. Kakimoto, "ATL-like marked atypical lymphocytosis associated with drug-induced hypersensitivity syndrome and human herpesvirus-6 reactivation," International Journal of Hematology, vol. 90, no. 5, pp. 648-650, 2009.
[47] Y. Fujino, M. Nakajima, H. Inoue, T. Kusuhara, and T. Yamada, "Human herpesvirus 6 encephalitis associated with hypersensitivity syndrome," Annals of Neurology, vol. 51, no. 6, pp. 771-774, 2002.

[48] V. Conilleau, A. Dompmartin, L. Verneuil, M. Michel, and D. Leroy, "Hypersensitivity syndrome due to 2 anticonvulsant drugs," Contact Dermatitis, vol. 41, no. 3, pp. 141-144, 1999.

[49] Y. Fujita, M. Hasegawa, K. Nabeshima et al., "Acute kidney injury caused by zonisamide-induced hypersensitivity syndrome," Internal Medicine, vol. 49, no. 5, pp. 409-413, 2010.

[50] I. Gentile, M. Talamo, and G. Borgia, "Is the drug-induced hypersensitivity syndrome (DIHS) due to human herpesvirus 6 infection or to allergy-mediated viral reactivation? Report of a case and literature review," BMC Infectious Diseases, vol. 10, p. 49, 2010.

[51] G. Roquin, M. Peres, N. Lerolle et al., "First report of lamotrigine-induced drug rash with eosinophilia and systemic symptoms syndrome with pancreatitis," Annals of Pharmacotherapy, vol. 44, no. 12, pp. 1998-2000, 2010.

[52] Y. Teraki, M. Shibuya, and S. Izaki, "Stevens-Johnson syndrome and toxic epidermal necrolysis due to anticonvulsants share certain clinical and laboratory features with druginduced hypersensitivity syndrome, despite differences in cutaneous presentations," Clinical and Experimental Dermatology, vol. 35, no. 7, pp. 723-728, 2010.

[53] K. Matsuda, T. Ohnuma, M. Fukuta et al., "Case reports and literature review: the association between reactivation of human herpes virus- 6 and peripheral white blood cell count in patients with carbamazepine-induced hypersensitivity syndrome," Progress in Neuro-Psychopharmacology and Biological Psychiatry, vol. 30, no. 4, pp. 751-754, 2006.

[54] B. Géraudie, M. Charrier, P. Bonnafous et al., "Quantitation of human herpesvirus-6A, $-6 \mathrm{~B}$ and -7 DNAs in whole blood, mononuclear and polymorphonuclear cell fractions from healthy blood donors," Journal of Clinical Virology, vol. 53, no. 2, pp. 151-155, 2012.

[55] K. S. Roush, R. K. Domiati-Saad, L. R. Margraf et al., "Prevalence and cellular reservoir of latent human herpesvirus 6 in tonsillar lymphoid tissue," American Journal of Clinical Pathology, vol. 116, no. 5, pp. 648-654, 2001.

[56] T. Yoshikawa, A. Fujita, A. Yagami et al., "Human herpesvirus 6 reactivation and inflammatory cytokine production in patients with drug-induced hypersensitivity syndrome," Journal of Clinical Virology, vol. 37, pp. S92-96, 2006.

[57] Y. Kano, M. Inaoka, and T. Shiohara, "Association Between Anticonvulsant Hypersensitivity Syndrome and Human Herpesvirus 6 Reactivation and Hypogammaglobulinemia," Archives of Dermatology, vol. 140, no. 2, pp. 183-188, 2004.

[58] Y. Aihara, S. Ito, M. Aihara, Y. Kobayashi, and S. Yokota, "Different patterns of cytokines, ECP and immunoglobulin profiles at two adverse drug reactions in a patient," Pediatrics International, vol. 47, no. 6, pp. 616-621, 2005.

[59] Y. Kano, M. Seishima, and T. Shiohara, "Hypogammaglobulinemia as an early sign of drug-induced hypersensitivity syndrome," Journal of the American Academy of Dermatology, vol. 55, no. 4, pp. 727-728, 2006.

[60] M. T. Caserta, M. P. McDermott, S. Dewhurst et al., "Human herpesvirus 6 (HHV6) DNA persistence and reactivation in healthy children," Journal of Pediatrics, vol. 145, no. 4, pp. 478484, 2004.

[61] K. Tanaka-Taya, J. Sashihara, H. Kurahashi et al., "Human herpesvirus 6 (HHV-6) is transmitted from parent to child in an integrated form and characterization of cases with 
chromosomally integrated HHV-6 DNA," Journal of Medical Virology, vol. 73, no. 3, pp. 465-473, 2004.

[62] S.-O. Lee, R. A. Brown, and R. R. Razonable, "Clinical significance of pretransplant chromosomally integrated human herpesvirus- 6 in liver transplant recipients," Transplantation, vol. 92, no. 2, pp. 224-229, 2011.

[63] S.-O. Lee, R. A. Brown, A. J. Eid, and R. R. Razonable, "Chromosomally integrated human herpesvirus-6 in kidney transplant recipients," Nephrology Dialysis Transplantation, vol. 26, no. 7, pp. 2391-2393, 2011.

[64] K. N. Ward, H. N. Leong, E. P. Nacheva et al., "Human herpesvirus 6 chromosomal integration in immunocompetent patients results in high levels of viral DNA in blood, sera, and hair follicles," Journal of Clinical Microbiology, vol. 44, no. 4, pp. 1571-1574, 2006.

[65] L. Potenza, P. Barozzi, G. Rossi et al., "May the indirect effects of cihhv- 6 in transplant patients be exerted through the reactivation of the viral replicative machinery?" Transplantation, vol. 92, no. 9, pp. e49-e51, 2011.

[66] C. B. Hall, M. T. Cassrta, K. C. Schnabel et al., "Transplacental congenital human herpesvirus 6 infection caused by maternal chromosomally integrated virus," Journal of Infectious Diseases, vol. 201, no. 4, pp. 505-507, 2010.

[67] M. Daibata, T. Taguchi, Y. Nemoto, H. Taguchi, and I. Miyoshi, "Inheritance of chromosomally integrated human herpesvirus 6 DNA," Blood, vol. 94, no. 5, pp. 1545-1549, 1999.

[68] O. Lohi, M. Arola, I. Lautenschlager, E. P. Nacheva, and K. Vettenranta, "A high circulating copy number of HHV6 due to chromosomal integration in a child with acute lymphoblastic leukemia," Pediatric Blood and Cancer, vol. 55, no. 6, pp. 1236-1238, 2010.

[69] V. Strenger, C. Urban, W. Schwinger, E. P. Nacheva, and S. W. Aberle, "Transmission of chromosomally integrated HHV-6 by bone marrow transplantation," Pediatric Blood and Cancer, vol. 56, no. 1, pp. 171-171, 2011.

[70] P. J. de Pagter, A. Virgili, E. Nacheva, D. van Baarle, R. Schuurman, and J. J. Boelens, "Chromosomally integrated human herpesvirus 6: transmission via cord blood-derived unrelated hematopoietic stem cell transplantation," Biology of Blood and Marrow Transplantation, vol. 16, no. 1, pp. 130-132, 2010.

[71] R. T. Kamble, D. A. Clark, H. N. Leong, H. E. Heslop, M. K. Brenner, and G. Carrum, "Transmission of integrated human herpesvirus-6 in allogeneic hematopoietic stem cell transplantation," Bone Marrow Transplantation, vol. 40, no. 6, pp. 563-566, 2007.

[72] K. N. Ward, N. J. Andrews, C. M. Verity, E. Miller, and E. M. Ross, "Human herpesviruses- 6 and -7 each cause significant neurological morbidity in Britain and Ireland," Archives of Disease in Childhood, vol. 90, no. 6, pp. 619-623, 2005.

[73] H. Watanabe, M. Daibata, M. Tohyama, J. Batchelor, K. Hashimoto, and M. Iijima, "Chromosomal integration of human herpesvirus 6 DNA in anticonvulsant hypersensitivity syndrome [12]," British Journal of Dermatology, vol. 158, no. 3, pp. 640-642, 2008.

[74] A. V. M. Brands-Nijenhuis, I. H. M. van Loo, H. C. Schouten, and M. van Gelder, "Temporal relationship between HHV 6 and graft vs host disease in a patient after haplo-identical SCT and severe T-cell depletion," Bone Marrow Transplantation, 2010.

[75] Y. Suzuki, R. Inagi, T. Aono, K. Yamanishi, and T. Shiohara, "Human herpesvirus 6 infection as a risk factor for the development of severe drug-induced hypersensitivity syndrome," Archives of Dermatology, vol. 134, no. 9, pp. 1108-1112, 1998.
[76] T. Shiohara and Y. Kano, "A complex interaction between drug allergy and viral infection," Clinical Reviews in Allergy and Immunology, vol. 33, no. 1-2, pp. 124-133, 2007.

[77] M. G. Neuman, I. M. Malkiewicz, E. J. Phillips et al., "Monitoring adverse drug reactions to sulfonamide antibiotics in human immunodeficiency virus-infected individuals," Therapeutic Drug Monitoring, vol. 24, no. 6, pp. 728-736, 2002.

[78] M. Inaoka, "Innate immunity and hypersensitivity syndrome," Toxicology, vol. 209, no. 2, pp. 161-163, 2005.

[79] L. Mardivirin, V. Descamps, A. Lacroix, S. Delebassée, and S. Ranger-Rogez, "Early effects of drugs responsible for DRESS on HHV-6 replication in vitro," Journal of Clinical Virology, vol. 46, no. 3, pp. 300-302, 2009.

[80] Y. Kano, K. Sakuma, and T. Shiohara, "Sclerodermoid graftversus-host disease-like lesions occurring after drug-induced hypersensitivity syndrome," British Journal of Dermatology, vol. 156, no. 5, pp. 1061-1063, 2007.

[81] T. Watanabe, H. Nakashima, H. Ohmatsu, N. Sakurai, T. Takekoshi, and K. Tamaki, "Detection of human herpesvirus6 transcripts in carbamazepine-induced hypersensitivity syndrome by in situ hybridization," Journal of Dermatological Science, vol. 54, no. 2, pp. 134-136, 2009.

[82] J. A. Carlson, A. Perlmutter, E. Tobin, D. Richardson, and A. Rohwedder, "Adverse antibiotic-induced eruptions associated with Epstein Barr virus infection and showing KikuchiFujimoto disease-like histology," American Journal of Dermatopathology, vol. 28, no. 1, pp. 48-55, 2006.

[83] M. Tohyama, Y. Yahata, M. Yasukawa et al., "Severe hypersensitivity syndrome due to sulfasalazine associated with reactivation of human herpesvirus 6," Archives of Dermatology, vol. 134, no. 9, pp. 1113-1117, 1998.

[84] N. Mitani, M. Aihara, Y. Yamakawa et al., "Drug-induced hypersensitivity syndrome due to cyanamide associated with multiple reactivation of human herpesviruses," Journal of Medical Virology, vol. 75, no. 3, pp. 430-434, 2005.

[85] V. Descamps, E. Mahe, N. Houhou et al., "Drug-induced hypersensitivity syndrome associated with Epstein-Barr virus infection," British Journal of Dermatology, vol. 148, no. 5, pp. 1032-1034, 2003.

[86] N. Yawalkar, M. Shrikhande, Y. Hari, H. Nievergelt, L. R. Braathen, and W. J. Pichler, "Evidence for a role for IL-5 and eotaxin in activating and recruiting eosinophils in druginduced cutaneous eruptions," Journal of Allergy and Clinical Immunology, vol. 106, no. 6, pp. 1171-1176, 2000.

[87] G. J. Gleich, "Mechanisms of eosinophil-associated inflammation," Journal of Allergy and Clinical Immunology, vol. 105, no. 4, pp. 651-663, 2000.

[88] B. R. Silk and A. P. Roome, "Herpes encephalitis treated with intravenous idoxuridine," Lancet, vol. 1, no. 7643, pp. 411412, 1970.

[89] W. Hryniuk, J. Foerster, M. Shojania, and A. Chow, "Cytarabine for herpesvirus infections," Journal of the American Medical Association, vol. 219, no. 6, pp. 715-718, 1972.

[90] R. J. Whitley, S. J. Soong, and M. S. Hirsch, "Herpes simplex encephalitis. Vidarabine therapy and diagnostic problems," New England Journal of Medicine, vol. 304, no. 6, pp. 313-318, 1981.

[91] A. Suzuki, R. J. Andrade, E. Bjornsson et al., "Drugs associated with hepatotoxicity and their reporting frequency of liver adverse events in vigibase: unified list based on international collaborative work," Drug Safety, vol. 33, no. 6, pp. 503-522, 2010 . 


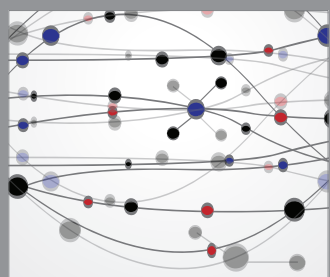

The Scientific World Journal
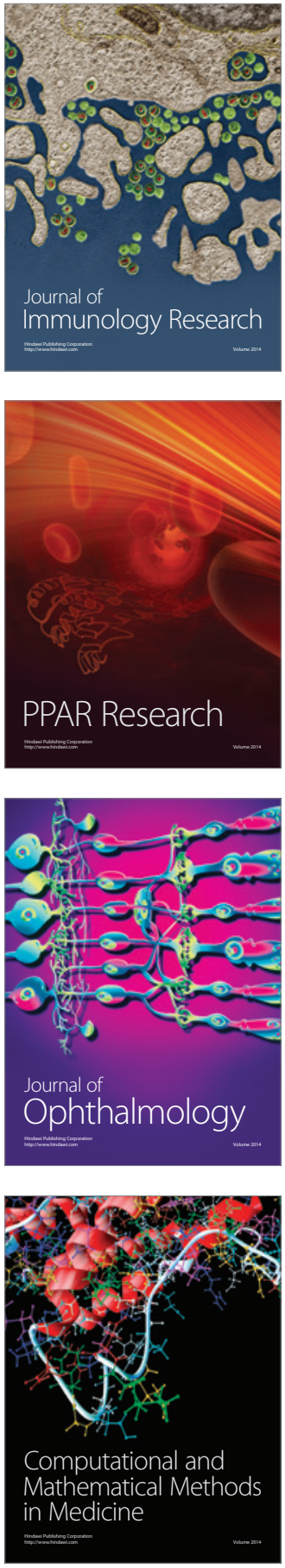

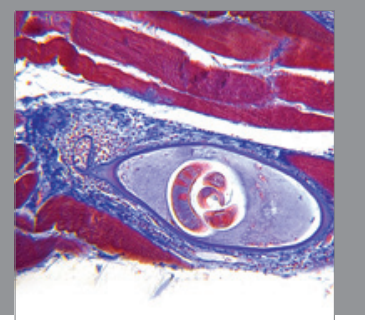

Gastroenterology

Research and Practice
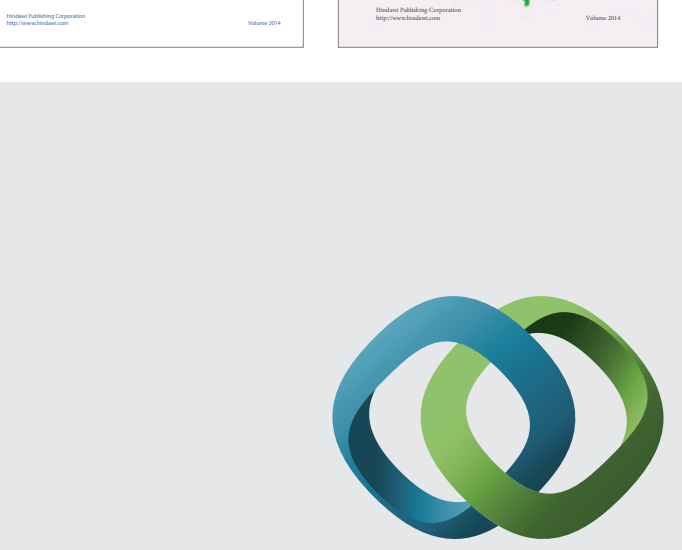

\section{Hindawi}

Submit your manuscripts at

http://www.hindawi.com
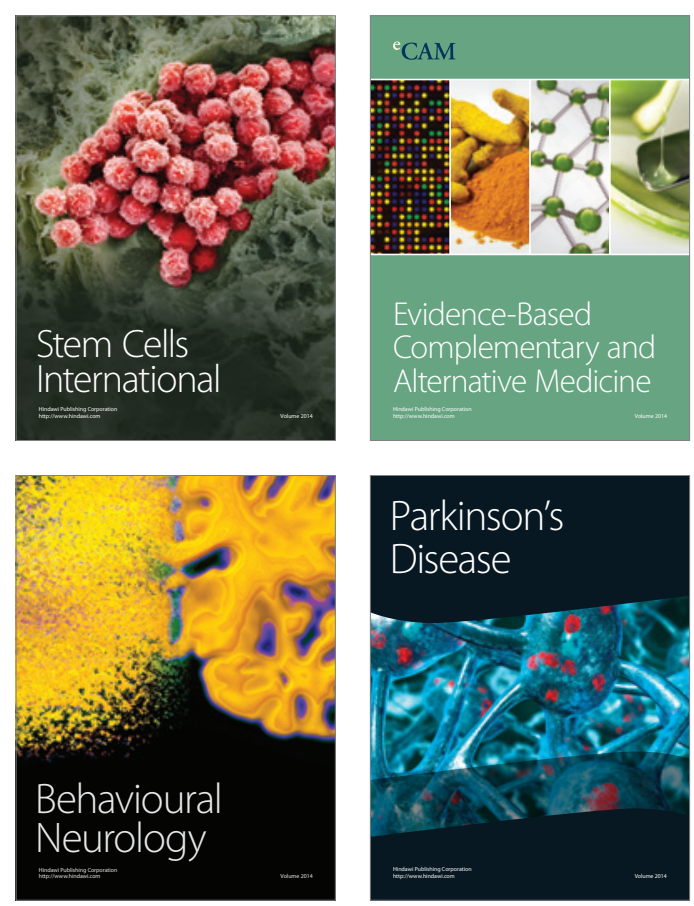

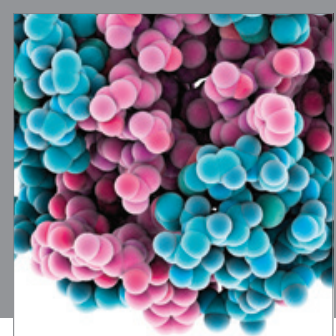

Journal of
Diabetes Research

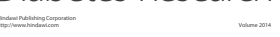

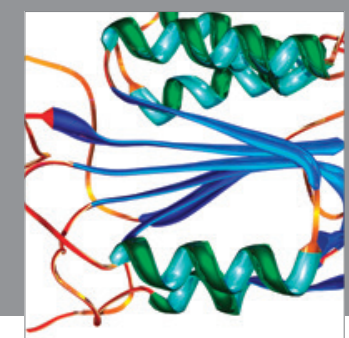

Disease Markers
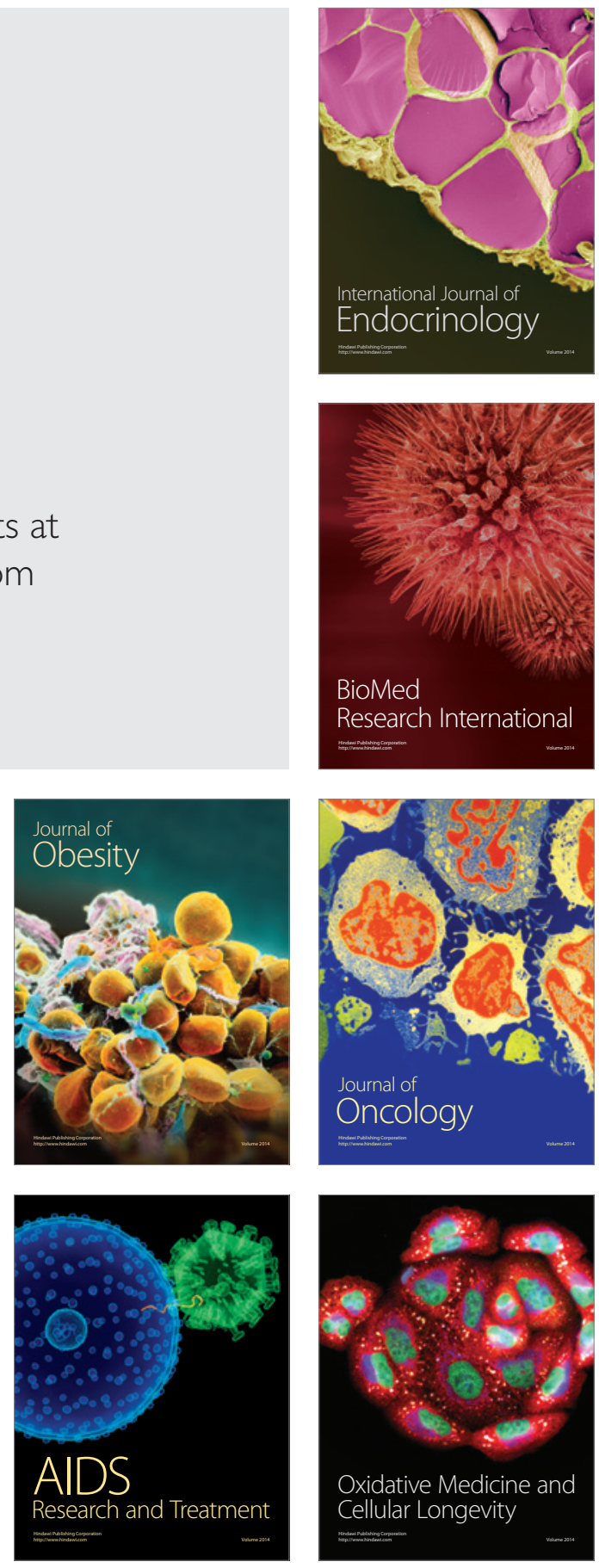